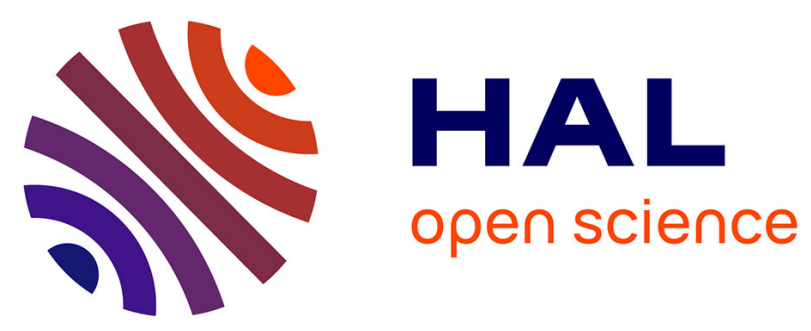

\title{
Electron Precise Sodium Carbaboride Nanocrystals from Molten Salts: Single Sources to Boron Carbides
}

\author{
Simon Delacroix, Fernando Igoa, Yang Song, Yann Le Godec, Cristina
}

Coelho-Diogo, Christel Gervais, Gwenaelle Rousse, David Portehault

\section{- To cite this version:}

Simon Delacroix, Fernando Igoa, Yang Song, Yann Le Godec, Cristina Coelho-Diogo, et al.. Electron Precise Sodium Carbaboride Nanocrystals from Molten Salts: Single Sources to Boron Carbides. Inorganic Chemistry, 2021, The Inorganic Chemistry of Nanoparticles, 60 (7), pp.4252-4260. 10.1021/acs.inorgchem.0c03501 . hal-03145234

\section{HAL Id: hal-03145234 https://hal.sorbonne-universite.fr/hal-03145234}

Submitted on 16 Nov 2021

HAL is a multi-disciplinary open access archive for the deposit and dissemination of scientific research documents, whether they are published or not. The documents may come from teaching and research institutions in France or abroad, or from public or private research centers.
L'archive ouverte pluridisciplinaire HAL, est destinée au dépôt et à la diffusion de documents scientifiques de niveau recherche, publiés ou non, émanant des établissements d'enseignement et de recherche français ou étrangers, des laboratoires publics ou privés. 


\section{Electron precise sodium carbaboride nanocrystals}

\section{from molten salts: single sources to boron carbides}

Simon Delacroix, ${ }^{1,2}$ Fernando Igoa, ${ }^{1,2}$ Yang Song, ${ }^{1}$ Yann Le Godec, ${ }^{2, *}$ Cristina CoelhoDiogo, ${ }^{3}$ Christel Gervais, ${ }^{1}$ Gwenaelle Rousse, ${ }^{4}$ David Portehault ${ }^{1, *}$

${ }^{1}$ Sorbonne Université, CNRS, Laboratoire de Chimie de la Matière Condensée de Paris (CMCP), 4 place Jussieu, F-75005, Paris, France

${ }^{2}$ Sorbonne Université, CNRS, MNHN, IRD, Institut de Minéralogie, de Physique des Matériaux et de Cosmochimie (IMPMC), 4 place Jussieu, F-75005, Paris, France

${ }^{3}$ Sorbonne Université, CNRS, Institut des Matériaux de Paris Centre (IMPC), 4 place Jussieu, F-75005, Paris, France

${ }^{4}$ Collège de France, Sorbonne Université, Chimie du Solide et de l'Energie (CSE), 75231 Paris Cedex 05, France

*Corresponding authors:

david.portehault@sorbonne-universite.fr yann.le_godec@sorbonne-universite.fr 


\begin{abstract}
Boron-rich solids exhibit specific crystal structures and unique properties, which are only very scarcely addressed in nanoparticles. In this work we address the original inorganic structural chemistry and reactivity of boron-rich nanoparticles, by reporting the first occurence of sodium carbaboride nanocrystals based on the $\mathrm{NaB}_{5} \mathrm{C}$ crystal structure. To design these sub-10 nm nano-objects, we use liquid-phase synthesis in molten salts at $900{ }^{\circ} \mathrm{C}$. By combining a set of characterization tools including powder X-ray powder diffraction, transmission electron microscopy, solid state nuclear magnetic resonance coupled to DFT modelling and X-ray photoelectron spectroscopy, we demonstrate that these nanocrystals deviate from the ideal stoichiometry reported for the bulk compound. We suggest that the carbon and sodium contents compensate each other to ensure that the octahedral cluster-based framework is stabilized by fulfilling an electron counting rule. These nanocrystals encompass substituted octahedral covalent structural building units not reported in the related bulk compound. They then shed a new light on the ability of nanoparticles to host wide solid solution ranges in covalent solids and then to yield new solids. We finally show that these nanocrystals are efficient single sources of boron and carbon to form a nanostructured boron carbide, thus paving a way to new nanostructured materials.
\end{abstract}




\section{Introduction}

Inorganic chemistry of boron-rich solids is driven by the trend of boron to build covalent bonds with itself. ${ }^{1,2}$ These covalent bonds account for many unique properties, but little is known on their occurrence in nanoparticles and their impact on the nanoparticles properties. Metal hexaborides (Figure 1, Movie S1) are built on such bonds that yield a covalent framework made of $\mathrm{B}_{6}$ octahedral units. Although known for a long time, metal hexaborides (Figure 1, Movie S1) have been the focus of renewed interest in recent years. Some of them are well known to exhibit field emission (rare earth hexaborides) and thermoelectric (alkaline earth hexaborides) properties, but new and unexpected behaviors have emerged within the last years: $\mathrm{LaB}_{6}$ exhibits near-infrared surface plasmon resonance ${ }^{3}$ while $\mathrm{SmB}_{6}$ is a Kondo insulator coupled to a specific conductive surface state, ${ }^{4}$ which might be related to topological features. ${ }^{4}$ Both examples show the importance of controlling the composition, but also the surface states and the surface-to-volume ratio of metal hexaborides in order to control optical and conduction properties, among others. Nanocrystal design provides interesting perspectives in this respect.
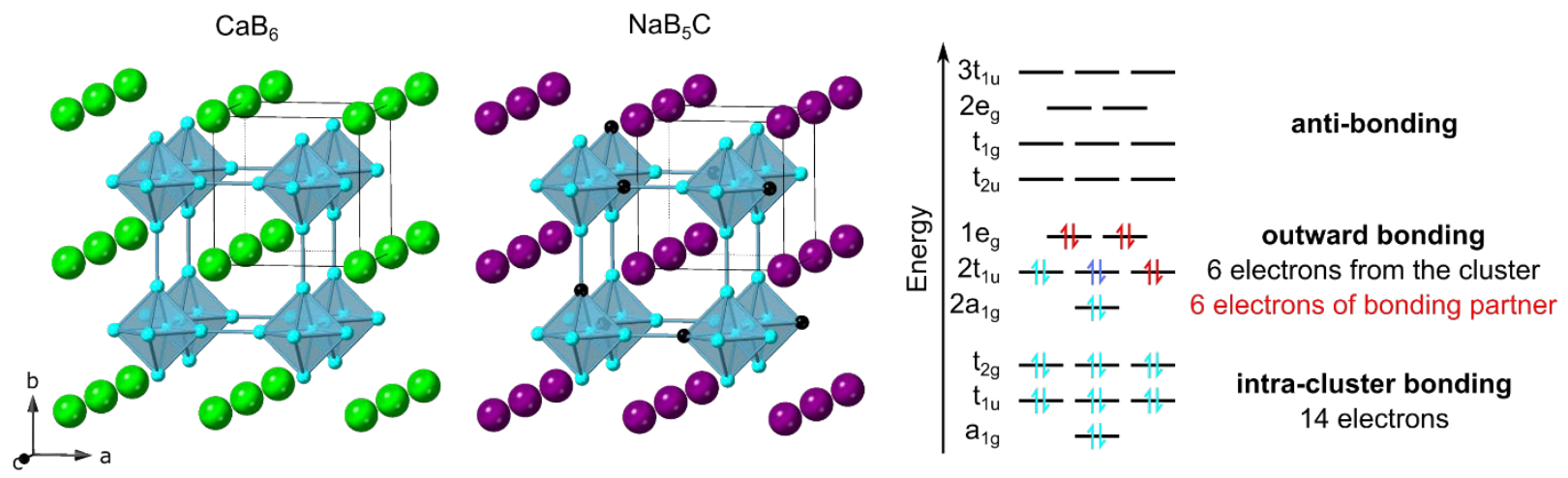

Figure 1. Crystal structures of $\mathrm{NaB}_{5} \mathrm{C}$ and $\mathrm{CaB}_{6}$. Boron, carbon, sodium and calcium atoms are in blue, black, purple and green, respectively. The octahedral clusters are represented in light blue. For $\mathrm{NaB}_{5} \mathrm{C}$, the carbon atoms are placed randomly in each unit cell. The molecular orbital diagram corresponds to one octahedral cluster, analog to the molecular $\mathrm{B}_{6} \mathrm{H}_{6}{ }^{2-}$ anion. Light blue arrows account for electrons provided by 6 boron atoms into a $\mathrm{B}_{6}$ octahedral cluster. The 6 red arrows correspond to the bonding partners building 6 outward 2center-2electron bonds ( $\mathrm{B}-\mathrm{H}$ bonds in $\mathrm{B}_{6} \mathrm{H}_{6}{ }^{2-}$ analog, inter-cluster $\mathrm{B}-\mathrm{B}$ bonds in the hexaboride). The remaining 2 blue arrows account for the two additional electrons needed for fully stabilizing the framework. 
The theoretical frame explaining the stability and conduction properties of many metal hexaborides has been provided early by Longuet-Higgins and de V. Roberts, ${ }^{5,6}$ who have built an analogy between the octahedral $\mathrm{B}_{6}$ clusters building the hexaboride framework (Figure 1) and the $\mathrm{B}_{6} \mathrm{H}_{6}{ }^{2-}$ anion, thus referring to Wade's rules. ${ }^{7-9}$ According to the molecular orbital diagram of a $\mathrm{B}_{6}$ unit (Figure 1), the anion reaches a stable closed shell configuration and the $\mathrm{B}_{6}$ extended framework is stable when each octahedron is provided with 20 electrons. These 20 electrons include 14 electrons filling the intra-octahedron bonding orbitals, and 6 electrons populating each of the 6 outwardly bonding orbitals at each corner of the octahedron to build 2center-2electron inter-octahedra bonds (or B-H bonds for the analog $\mathrm{B}_{6} \mathrm{H}_{6}{ }^{2-}$ anion). The $\mathrm{B}_{6}$ octahedron provides on itself 18 electrons and the metal encaged between the octahedral units supplies 2 electrons in the formalism of the Zintl concept. ${ }^{10,11}$ Overall, with divalent metal cations, like alkaline earth, only the bonding states are filled, which yields semiconductors. In this model, an additional electron, provided with trivalent metal cations would yield metallic compounds, like $\mathrm{LaB}_{6}$, although more complex effects such as strong electron correlation could change the outcome and yield bulk semiconductors, like $\mathrm{SmB}_{6}$. In this frame, replacing the metal with an alkali metal supplying only one electron would fail to provide full stabilization, which explains the near complete absence of alkali hexaborides ${ }^{6}$ except $\mathrm{Li}_{2} \mathrm{~B}_{6}{ }^{12}$ and the notable case of metal deficient $\mathrm{KB}_{6}$, for which a consensus has not been reached. ${ }^{1,13,14}$ To go beyond this restriction and in their effort to discover new boron-rich borides of alkali metals, B. Albert and K. Schmitt ${ }^{15,16}$ have discovered ternary compounds with the hexaboride structure: alkali carbaborides $\mathrm{NaB}_{5} \mathrm{C}$ and $\mathrm{KB}_{5} \mathrm{C}$, which are actually the only carbaborides of sodium and potassium. ${ }^{1}$ In these compounds, the $\mathrm{B}_{6}$ units in hexaborides are replaced by $\mathrm{B}_{5} \mathrm{C}$ octahedra. Substituting one boron for one carbon atom in each octahedron provides the missing electron to fulfill the maximal stabilization conditions of the extended octahedral framework. ${ }^{15,16}$ 
According to this model, one would expect that deviations from the ideal stoichiometry would destabilize the solids. These theoretical considerations have however been difficult to confirm experimentally up to now because of the absence of a local probe for investigating the boron/carbon local environment. On a more fundamental side, given the propensity of nanocrystals to accommodate larger strains and deviations to bulk phase diagrams, ${ }^{17}$ the question arises as to whether stoichiometry deviation could occur or be facilitated in alkali carbaboride nanocrystals and if they could host new covalent building units could arise.

In addition, the reactivity of $\mathrm{NaB}_{5} \mathrm{C}$ and $\mathrm{KB}_{5} \mathrm{C}$ is a virgin field, while other alkali-based compounds of p-block elements are known to exhibit interesting phase transformations when the alkali metal can be eliminated, as in the case of the evolution of sodium silicide $\mathrm{Na}_{4} \mathrm{Si}_{4}$ to silicon clathrates. ${ }^{18}$ A similar chemical evolution for alkali carbaborides could yield boron carbides, of high interest for their hardness ${ }^{19}$ and photocatalytic ${ }^{20}$ properties. Designing alkali carbaboride nanocrystals would be the key to open a new avenue to nanostructured boron-rich carbides. Again, such a transformation would raise the more general fundamental question of the reactivity of nanoparticles based on covalent bonds.

Addressing the questions of the stoichiometry of alkali carbaboride nanocrystals and of their reactivity requires synthesizing these compounds for the first time as nano-objects, while all previous works have dealt with macroscale crystals formed from the elements, especially strongly inert boron (Table S1). ${ }^{15,16,21,22}$ The search for a pathway towards alkali carbaboride nanocrystals then sits in the last decade extensive research on the synthesis of metal boride nanoparticles. ${ }^{23}$ One of the general routes to reach this aim is the synthesis in molten salts, ${ }^{24,25}$ mostly focused on transition metal or rare-earth metal borides ${ }^{3,26-33}$ but recently extended to a lithium boride. ${ }^{34}$ The method should then be suitable to reach nanocrystals of other alkali-based boron-rich solids, including alkali carbaborides. 
In this work, we provide the first occurrence of $\mathrm{NaB}_{5} \mathrm{C}$ nanocrystals, by using molten salts as solvent and reagent. The choice of reactive boron and carbon precursors and of liquidphase reaction provides ideal conditions to trigger fast nucleation of the crystals and then to limit the particle size in the sub-10 $\mathrm{nm}$ range. We then use $\mathrm{NaB}_{5} \mathrm{C}$ nanocrystals as case-study to address possible deviations from the ideal stoichiometry. We finally show how $\mathrm{NaB}_{5} \mathrm{C}$ nanocrystals can be used as single sources of boron and carbon towards boron carbide nanocrystals.

\section{Methods}

Sodium borohydride (98\%, Alfa Aesar), sodium iodide ( $>99.5 \%$, Sigma Aldrich), polyethylene $\left(\mathrm{M}_{\mathrm{w}}=35000 \mathrm{~g} \mathrm{~mol}^{-1}\right.$, Sigma Aldrich), methanol (VWR Normapur grade) were used as received and handled under argon atmosphere in a glovebox $\left(\mathrm{H}_{2} \mathrm{O}<0.5 \mathrm{ppm}, \mathrm{O}_{2}<0.5\right.$ ppm) and with standard Schlenk techniques.

To synthesize $\mathrm{NaB}_{5} \mathrm{C}, 600 \mathrm{mg}$ of sodium borohydride $(15.9 \mathrm{mmol})$ was grinded with 5 $\mathrm{g}$ of sodium iodide and $285 \mathrm{mg}$ of polyethylene (10.2 mmol, C:B atomic ratio of 1:2.75) during two minutes at $20 \mathrm{~Hz}$ (Retsch MM400, $50 \mathrm{~mL}$ stainless steel bowls filled with one ball) to obtain an homogeneous finely ground powder. The mixture was heated at $900{ }^{\circ} \mathrm{C}$ under argon during two hours in a crucible, and then cooled down to room temperature. The synthesis was run in either molybdenum or $h$-BN crucibles. The reaction mixture was washed with methanol by ten cycles of centrifugation and redispersion. The powder was dried under vacuum for $12 \mathrm{~h}$ before being stored under argon. $156 \mathrm{mg}$ was typically recovered after synthesis, which corresponds to a yield of $55 \%$ versus the boron precursor. The synthesis was reproduced at least 20 times to ensure reproducibility. 
Boron carbide was synthesized by thermal decomposition of sodium carbaboride. The initial powder was placed into a $h$-BN crucible, placed itself into a horizontal tubular oven, which was purged with Ar flow for $1 \mathrm{~h}$ before being heated under argon flow up to $1200{ }^{\circ} \mathrm{C}$ at a heating rate of $5^{\circ} \mathrm{C} \mathrm{min}^{-1}$. Then the temperature was dwelled for $12 \mathrm{~h}$ before stopping heating and letting the oven cool down naturally. The resulting powder was washed with methanol by cycles of centrifugation and redispersion until a conductivity of $4 \mu \mathrm{S} \cdot \mathrm{cm}^{-1}$ in the supernatant was achieved. The sample was stored in air.

Powder XRD was performed with a Bruker D8 Advance diffractometer in the BraggBrentano $\theta-\theta$ geometry with a $\mathrm{CuK} \alpha$ sealed tube $\mathrm{X}$-ray source $(\lambda=1.5418 \AA)$. Powder patterns were collected in the $2 \theta$ range $10-120^{\circ}$ with a $0.1^{\circ}$ step and collecting data for $20 \mathrm{~s} / \mathrm{step}$ for $\mathrm{NaB}_{5} \mathrm{C}, 10-120^{\circ}$ with a $0.05^{\circ}$ step and $5 \mathrm{~s} /$ step for $\mathrm{B}_{4} \mathrm{C}$ samples. The reference crystallographic structure of $\mathrm{NaB}_{5} \mathrm{C}$ and $\mathrm{B}_{4} \mathrm{C}$ were taken from the ICSD database (408930 and 79958 cards, respectively) before being refined according to the Rietveld method using the FullProf Suite software. $^{35}$

XPS spectra were recorded on an Omicron spectrometer using an Al $\mathrm{K} \alpha$ source $(1486.7 \mathrm{eV})$ as the source energy. The binding energies were referenced versus the aliphatic C1s peak $(284.8 \mathrm{eV})$.

The specific area was evaluated by applying the BET method to a nitrogen sorption isotherm recorded at $77 \mathrm{~K}$ using a BELSORB-max apparatus after degassing the sample at 150 ${ }^{\circ} \mathrm{C}$ for $15 \mathrm{~h}$.

Transmission electron microscopy (TEM) images were acquired with a Technai Spirit 2 microscope operating at $120 \mathrm{kV}$. The powders were deposited on carbon-coated copper grids by solid-state deposition in an argon glovebox. Energy dispersive X-ray analysis (EDS) was performed on a Hitachi SU-70 scanning electron microscope. 
Raman spectroscopy was performed on the powder with a Kaiser Optical System Raman Analyzer RX1 Microprobe with a $785 \mathrm{~nm}$ laser diode.

Solid-state MAS NMR spectra were acquired on a Bruker AVANCE III 700 spectrometer (16.4 T magnet) operating at $v_{0}=224.68$ and $185.20 \mathrm{MHz}$ for ${ }^{11} \mathrm{~B}$ and ${ }^{23} \mathrm{Na}$ respectively and using a $3.2 \mathrm{~mm}$ Bruker probe. Powder samples were transferred to $\mathrm{ZrO}_{2}$ rotors and spun at a MAS rate of $20 \mathrm{kHz} .{ }^{1} \mathrm{H},{ }^{23} \mathrm{Na}$ and ${ }^{11} \mathrm{~B}$ chemical shifts were referenced to TMS, $0.1 \mathrm{M} \mathrm{NaCl}_{(\mathrm{aq})}$ and $\mathrm{BF}_{3} \cdot \mathrm{OEt}_{2}$, respectively.

Different models were obtained starting from the crystalline structure of $\mathrm{NaB}_{5} \mathrm{C}^{16}$ and using $2 \times 2 \times 2$ and $3 \times 3 \times 3$ supercells in which carbon atoms were randomly positioned in substitution of one or two borons among $\mathrm{B}_{6}$ octahedra. In addition, $\mathrm{Na}$ vacancies were introduced in some cases as described more precisely later in the text. All atomic positions were then relaxed with the VASP (Vienna Ab-initio Simulation Package) code ${ }^{36}$ based on the Kohn-Sham Density Functional Theory (DFT) and using a plane-wave pseudopotential approach. The cells parameters were fixed to X-ray diffraction parameters during geometry optimizations. The NMR parameters were then calculated within the Kohn-Sham DFT using the QUANTUM-ESPRESSO code ${ }^{37}$ keeping the atomic positions equal to the values previously calculated with VASP. The PBE generalized gradient approximation ${ }^{38}$ was used and the valence electrons were described by norm conserving pseudopotentials ${ }^{39}$ in the Kleinman Bylander form. ${ }^{40}$ The shielding tensor was computed using the Gauge Including Projector Augmented Wave (GIPAW) approach, ${ }^{41}$ which enables the reproduction of the results of a fully converged all electron calculation. The isotropic chemical shift $\delta_{i s o}$ is defined as $\delta_{i s o}=-$ $\left[\sigma-\sigma_{r e f}\right]$ where $\sigma$ is the isotropic shielding and $\sigma_{r e f}$ is the isotropic shielding of the same nucleus in a reference system. In the present case, the comparison between the experimental $\delta_{i s o}$ and calculated $\sigma_{\text {iso }}{ }^{11} \mathrm{~B}$ chemical shift values for $\mathrm{B}_{2} \mathrm{O}_{3}\left(\delta_{\text {iso }}=14.6 \mathrm{ppm}\right)(\mathrm{ICSD}$ reference card 16021$)$ was used for ${ }^{11} \mathrm{~B}$ while for ${ }^{23} \mathrm{Na}, \sigma_{\text {ref }}$ was fixed so that the average sum of experimental and 
calculated shifts of a series of sodium phosphates and silicates coincide. ${ }^{42}$ The principal components $V_{x x}, V_{y y}$, and $V_{z z}$ of the electric field gradient (EFG) tensor were obtained by diagonalisation of the calculated tensor giving access to the quadrupolar coupling constant $C_{Q}$ and the asymmetry parameter $\eta_{Q}$, which are defined as : $C_{Q}=e Q V_{z z} / h$ and $\eta_{Q}=\left(V_{y y}-V_{x x}\right) / V_{z z}$ ( $e$ is the proton charge, $h$ Planck's constant and $Q$ the quadrupole moment of the considered nucleus). The $Q$ value reported by Pyykkö ${ }^{43}$ was used in the calculations for ${ }^{11} \mathrm{~B}(40.5 \mathrm{mb})$ and ${ }^{23} \mathrm{Na}(104 \mathrm{mb})$. Calculated spectra were then plotted using the DMFit program. ${ }^{44}$

\section{Results and discussion}

$\mathrm{NaB}_{5} \mathrm{C}$ nanoparticles were synthesized by using sodium borohydride and polyethylene as boron and carbon sources respectively. The reaction was performed at $900{ }^{\circ} \mathrm{C}$ in molten sodium iodide (melting point $661{ }^{\circ} \mathrm{C}$ ), which acted as liquid medium and sodium source. The sample comprises exclusively slightly elongated cubic nanoparticles with a size distribution centered at $7 \mathrm{~nm}$, and edge lengths ranging from 2 to $14 \mathrm{~nm}$ (Figure $\mathbf{2 A}$ and $\mathbf{2 B}$ ). 


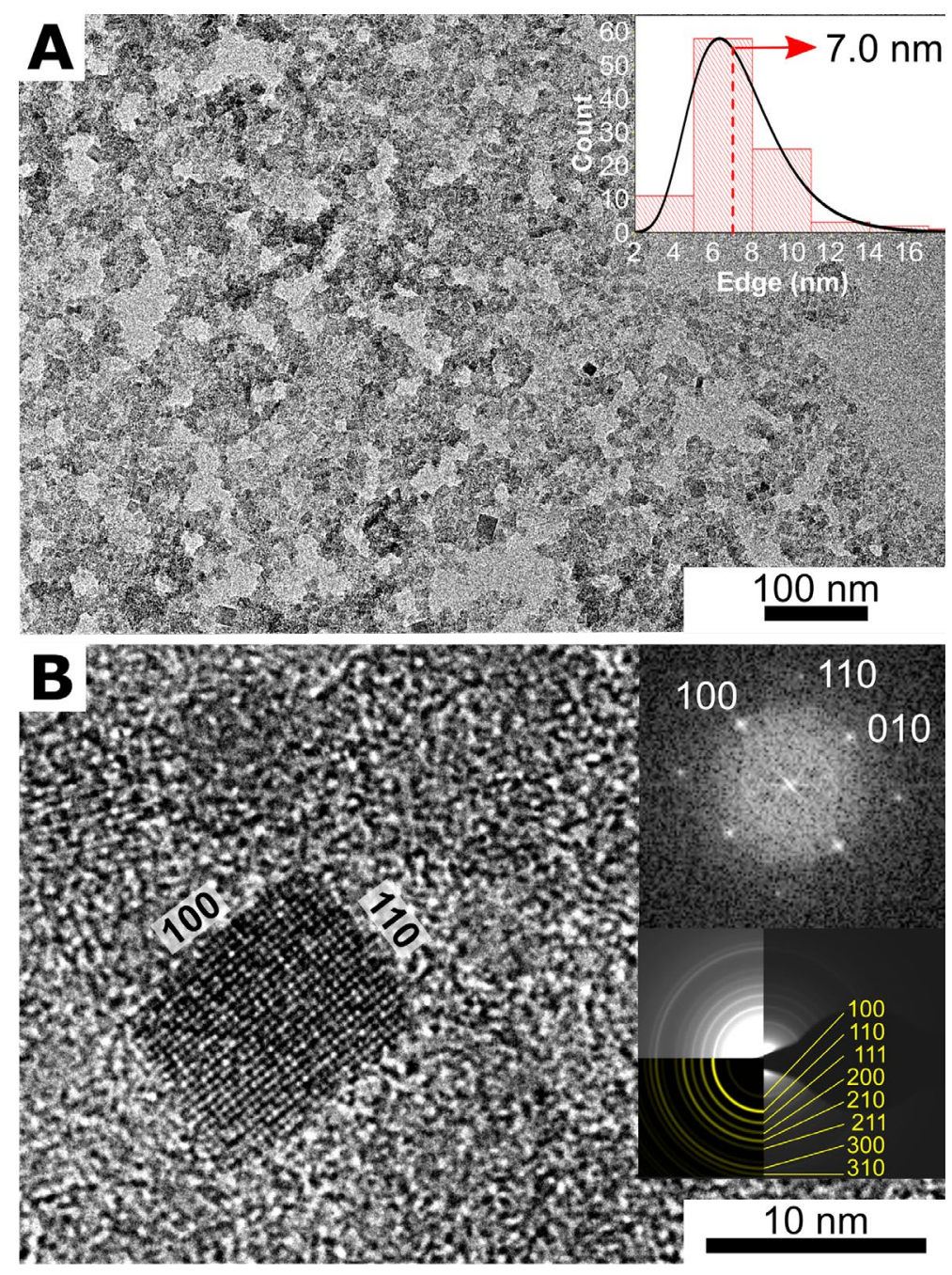

Figure 2. (A) TEM and (B) HRTEM images of $\mathrm{NaB}_{5} \mathrm{C}$-related sodium carbaboride nanocrystals. The corresponding size distribution is shown as inset in (A). The Fast Fourier Transform (FFT) of image (B) is shown as insert, together with the SAED pattern. They are fully indexed along the $\mathrm{NaB}_{5} \mathrm{C}$ structure.

The X-ray powder diffraction (XRD) pattern (Figure 3) is fully indexed along the cubic Pm$3 \mathrm{~m}$ space group of the $\mathrm{NaB}_{5} \mathrm{C}$ crystal structure. Rietveld refinement with this structure yields for the final model satisfactory conventional figures of merit $\left(R_{\mathrm{wp}}=5.41 \%, R_{\mathrm{B}}=0.66 \%, \chi^{2}=\right.$ 6.31). In a first step, the $\mathrm{XRD}$ pattern was fitted to the exact $\mathrm{NaB}_{5} \mathrm{C}$ stoichiometry (See Figure S1A-B $).{ }^{16}$ While this model seem appropriate $\left(R_{\mathrm{wp}}=7.42 \%, R_{\mathrm{B}}=1.00 \%, \chi^{2}=11.18\right)$, discrepancies with the experimental and reported data motivated further analysis. Firstly, the adjustment fails to fully account for the intensity of the (100) reflection at $21.6^{\circ}(\mathrm{Cu} \mathrm{K \alpha})$, which represents the largest relative error according to the difference curve. Secondly, the refined cell 
parameter $-4.0878(2) \AA$ - is slightly smaller than the reported one of $4.0925(1) \AA .{ }^{16}$ We have then refined atomic occupancies in order to further improve the agreement with experimental data. Three approaches were considered: refinement of only the $\mathrm{B} / \mathrm{C}$ ratio (model $\mathrm{I}$, Figure S1C-D), refinement of only the $\mathrm{Na}$ occupancy (model II, Figure S1E-F) and refinement of both the B/C ratio and the Na occupancy (modle III, Figure S1G-H). All three models coincide better with the experimental data (Figure S1), since they all influence the pattern by increasing the relative ratio of the (100) reflexion, as compared in Figure S1 against the (200) and (210) reflexions. However, model I yields a negative B occupancy that is not chemically valid. On the other hand, model II leads to the stoichiometry $\mathrm{Na}_{0.809} \mathrm{~B}_{5} \mathrm{C}$, which deviates from the electron counting rules described above. Model III enables to compensate possible $\mathrm{Na}$ vacancies with an increase in the carbon content to fulfill the overall electron counting rule in the B-C framework with 20 electrons per octahedral unit, provided the stoichiometry is restrained to $\mathrm{Na}_{1-\mathrm{x}} \mathrm{B}_{5-\mathrm{x}} \mathrm{C}_{1+\mathrm{x}}$. Accordingly, Rietveld refinement yields the composition of $\mathrm{Na}_{0.816} \mathrm{~B}_{4.816} \mathrm{C}_{1.184}$. The results from models II and III are indistinguishable in terms of figures of merit or visual inspection (Figure S1). However, model III satisfies the electron counting rule and is then privileged. The solid-state Nuclear Magnetic Resonance (NMR) discussed later further supports this choice. The refinement is clearly in better agreement with the experimental diagram compared to the refinement from the ideal $\mathrm{NaB}_{5} \mathrm{C}$ model (Figure S1). The bond lengths within and between the clusters are on average 1.74 and $1.63 \AA$ respectively for model III, which is in overall agreement with the reported octahedrabased framework of $\mathrm{NaB}_{5} \mathrm{C}$. The resulting stoichiometry corresponds to molar ratios $\mathrm{Na} / \mathrm{B}$ and $\mathrm{B} / \mathrm{C}$ of 0.17 and 4.07 , respectively, versus 0.20 and 5.00 for the tabulated $\mathrm{NaB}_{5} \mathrm{C}$ compound. ${ }^{16}$ According to the final Rietveld refinement of the XRD pattern, the crystallite size is $5.0 \mathrm{~nm}$ in agreement with the particle size from TEM, suggesting that each nanoparticle consists in a single crystal domain. This is confirmed by High resolution TEM (HRTEM) (Figure 2B). 
HRTEM is also in agreement with the $\mathrm{NaB}_{5} \mathrm{C}$ crystal structure. The $\mathrm{NaB}_{5} \mathrm{C}$ nanocrystals expose $\{100\}$ facets.

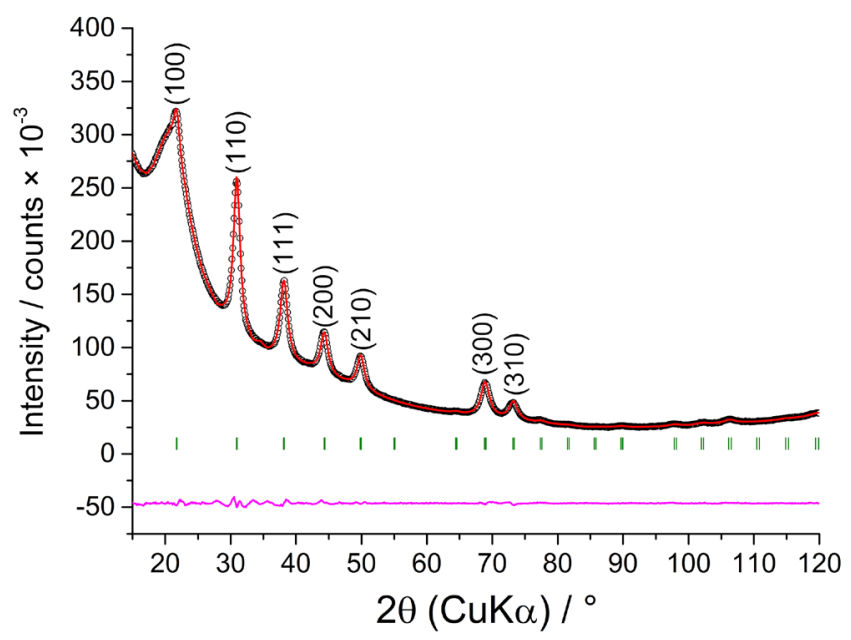

Figure 3. Rietveld refinement of the XRD pattern of the $\mathrm{NaB}_{5} \mathrm{C}$-related sodium carbaboride powder recovered after synthesis in molten sodium iodide: experimental pattern (dotted black), calculated pattern (red) and difference curve (purple). The green vertical bars correspond to the Bragg peak positions according to the $\mathrm{NaB}_{5} \mathrm{C}$ structure. The broad bump between 15 and $30^{\circ}$ is due to beam scattering by the protective PMMA plastic dome used to maintain the powder under protective argon atmosphere.

The composition of the material was confirmed by Energy dispersive X-ray spectroscopy (EDS), and X-ray photoelectron spectroscopy (XPS). Both techniques yield consistent molar Na/B ratios of 0.15 and 0.17 , respectively (Table S2). These values confirm the sodium sub-stoichiometry inferred by XRD compared to the ideal stoichiometry $\mathrm{NaB}_{5} \mathrm{C}$. The absence of any band characteristic of graphitic ordering on the Raman spectrum (Figure S2) suggests that the sample is exempt of layered carbonaceous by-products and of amorphous carbon, which usually exhibits a slight portion of staked graphitic layers, thus giving rise to a Raman signature. The presence of methanol at the surface of the nanocrystals was confirmed by ${ }^{1} \mathrm{H}$ solid-state nuclear magnetic resonance (Figure S3), showing two peaks characteristic of methanol. The detectable amount of methanol is related to the high specific surface measured by nitrogen sorption around $300 \mathrm{~m}^{2} \mathrm{~g}^{-1}$ according to the BET method. This high surface area 
also results in surface carbonaceous contamination during analysis (Table S2), which precludes any precise estimation of the carbon content within the nanocrystals by XPS or electron energy loss spectroscopy, at the opposite of the bulk $\mathrm{NaB}_{5} \mathrm{C}^{16}$

The surface states were then further probed by XPS (Figure S4). According to the deconvolution of $\mathrm{C} 1 \mathrm{~s}$ spectrum, four carbon chemical states were detected. The lowest binding energy peak at $283.06 \mathrm{eV}$ is assigned to C-B bonds. ${ }^{45} \mathrm{C}-\mathrm{O}$ bonds are also detected at 286.80 $\mathrm{eV}$. They could arise from contamination and/or surface reactivity with methanol. The peaks at $284.81 \mathrm{eV}$ and $289.04 \mathrm{eV}$ come from adventitious carbon contamination. ${ }^{45}$ The $\mathrm{B} 1 \mathrm{~s}$ spectrum was deconvoluted into three peaks. The component at $187.02 \mathrm{eV}$ corresponds to BB bond. ${ }^{45}$ The peak at $188.13 \mathrm{eV}$ is assigned to B-C bonds. ${ }^{45}$ Its relatively large FWHM indicates a distribution of boron chemical states round the B-C bonding boron, which could be explained by the various environments of boron atoms in the octahedra, with B atoms that can be linked to e.g. $3 \mathrm{~B}$ and $1 \mathrm{C}$, or $2 \mathrm{~B}$ and $2 \mathrm{C}$. The peak at $192.68 \mathrm{eV}$ is characteristic of oxidized boron which could be ascribed to the high reactivity of the sample when exposed to air, during transfer to the XPS analysis chamber. This high reactivity, also observed by the pyrophoric nature of the dried samples when exposed a few seconds to air, was not reported for bulk sodium carbaboride ${ }^{15,16}$ and is probably related to the small particle size and the very high surface-to-volume ratio. Despite surface oxidation and methanol adsorption, the particles are remarkably sodium borocarbide single nanocrystals. The consistency between the particle (TEM) and crystallite (XRD) sizes shows that oxidation impacts only the near surface of the nanocrystals when the samples are exposed only shortly to air.

The sub-stoichiometry of sodium we observe and the related carbon over-stoichiometry we propose for the sodium carbaboride nanocrystals are not in agreement with the ideal $\mathrm{NaB}_{5} \mathrm{C}$ composition. Besides, addressing the validity of the electron counting rule in octahedra-based boron-rich compounds has been difficult to perform experimentally until now because of the 
absence of a local probe for investigating the boron/carbon local environment. For these reasons, we have embarked on assessing the composition of the octahedra within sodium borocarbide nanocrystals by using ${ }^{11} \mathrm{~B}$ solid-state NMR.

The ${ }^{11} \mathrm{~B}$ solid-state NMR spectrum of $\mathrm{NaB}_{5} \mathrm{C}$ shows at least three broad signals centered around 15, 2 and -8 ppm (Figure 4). No NMR study of $\mathrm{AB}_{5} \mathrm{C}$ carbaborides has been reported and the case of boron carbides shows the complexity of assessing the structure of B and Cbased solids with ${ }^{11} \mathrm{~B}$ NMR.${ }^{46,47}$ For further assignment of the ${ }^{11} \mathrm{~B}$ NMR signals, the spectrum was compared to spectra calculated by DFT based on several structural models (Figure 5). These models have been specifically designed in order to assess the composition of the octahedral units $\mathrm{B}_{6-\mathrm{x}} \mathrm{C}_{\mathrm{x}}$ and the ordering between these units (details for the construction of these models are given in the experimental section). The first model named $\mathbf{1 C r a n d o m} 222$ accounts for the $\mathrm{NaB}_{5} \mathrm{C}$ composition and consists in a $2 \times 2 \times 2$ supercell with full $\mathrm{Na}$ occupancy with closed shell $\mathrm{B}_{5} \mathrm{C}$ octahedra where the carbon atom is at a random position in all octahedra. The second model named $\mathbf{0 C}-2 \mathrm{Crandom} 222$ also accounts for the $\mathrm{NaB}_{5} \mathrm{C}$ composition in a $2 \times 2 \times 2$ supercell with full $\mathrm{Na}$ occupancy and built on octahedra, but with six of them being $\mathrm{B}_{5} \mathrm{C}$ while the last two are one $\mathrm{B}_{6}$ and one $\mathrm{B}_{4} \mathrm{C}_{2}$ octahedron, respectively. This model enables assessing deviation from the electron counting rule, as $\mathrm{B}_{6}$ octahedra in the presence of $\mathrm{Na}$ cannot exhibit a 20-electrons closed shell. The third model named 1Crandom333 again accounts for the $\mathrm{NaB}_{5} \mathrm{C}$ composition. It is equivalent to the model $\mathbf{1 C}$ random 222 , but extended through a $3 \times 3 \times 3$ supercell, with full $\mathrm{Na}$ occupancy and closed shell $\mathrm{B}_{5} \mathrm{C}$ clusters where the carbon atom is randomly positioned. The fourth and fifth models account for the sodium substoichiometry and carbon over-stoichiometries described above, by considering $\mathrm{B}_{5} \mathrm{C}$ and $\mathrm{B}_{4} \mathrm{C}_{2}$ octahedra together. Each $\mathrm{B}_{4} \mathrm{C}_{2}$ unit is surrounded by a $\mathrm{Na}$ vacancy to ensure a closed shell octahedron. The fourth and fifth models are named 1Na-1C-2Crandom222 and 3Na-1C2Crandom333, respectively. They correspond to $2 \times 2 \times 2$ and $3 \times 3 \times 3$ supercells, respectively. 
1Na-1C-2Crandom 222 bears seven $\mathrm{B}_{5} \mathrm{C}$ octahedra and one $\mathrm{B}_{4} \mathrm{C}_{2}$ octahedron next to one $\mathrm{Na}$ vacancy. 3Na-1C-2Crandom 333 encompasses $24 \mathrm{~B}_{5} \mathrm{C}$ octahedra and $3 \mathrm{~B}_{4} \mathrm{C}_{2}$ octahedron next to $3 \mathrm{Na}$ vacancies. The atomic coordinates for the five structures were first DFT-relaxed before calculation of the NMR parameters through the gauge including projector augmented wave method. For comparison, NMR parameters were also calculated on a single cell (Figure 4), corresponding to a $\mathrm{NaB}_{5} \mathrm{C}$ composition that would be equivalent to a supercell with full $\mathrm{Na}$ occupancy and closed shell $\mathrm{B}_{5} \mathrm{C}$ octahedra where the carbon atom is at the same relative position in all octahedra. The results of these calculations are given in Figure 4 and Tables S3S8. The calculated NMR signals were then compared to the experimental ${ }^{11} \mathrm{~B}$ NMR spectrum (Figure 4). First, the discrepancy between the experimental spectrum and the one calculated for the single cell model shows that carbon atoms are not located in the same relative position in each octahedron. Second and overall, a slightly better accuracy seems to be reached for model 3-Na-1C-2Crandom333, which provides especially the best match of peak positions with the experimental spectrum. It should be noticed that the calculated parameters are not able to reproduce very accurately the experimental spectrum but since ${ }^{11} \mathrm{~B}$ calculated quadruplar coupling constants are relatively small while boron atoms are close in space, the spectrum shape is probably dominated by dipolar couplings, which were not taken into account by the calculation. To illustrate this, broadened gaussian shapes were used for all models keeping calculated chemical shifts. The corresponding calculated spectra are presented Figure S5. As expected, the global agreement is more satisfactory.

In order to further confirm the presence of sodium vacancies and assess the existence of $\mathrm{B}_{4} \mathrm{C}_{2}$ units, the ${ }^{23} \mathrm{Na}$ MAS spectrum of $\mathrm{NaB}_{5} \mathrm{C}$ was recorded. It shows a large signal centered around -6 ppm (Figure S6). This broadness could be either due to strong second-order quadrupolar effects or to a distribution of signals. To get clues on this question, the DFT calculated ${ }^{23} \mathrm{Na}$ spectra on the structural models previously described were compared to the 
experimental one (Figure S6). The calculated parameters are summarized in Tables S9-S10. It appears that second-order quadrupolar effects are relatively small with quadrupolar coupling constants calculated between 230 and $1140 \mathrm{kHz}$. Consequently, the width of the experimental line can only be reproduced with a distribution of chemical shift values as observed in random models. The agreement with the experimental spectrum could probably be improved with larger models that would possibly allow a larger distribution but this would render NMR calculations too difficult with the current calculators. It can nonetheless be noticed that the highest averaged quadrupolar coupling constant in absolute value $(>700 \mathrm{kHz})$, which favors the line broadening, is observed in 0C-2Crandom222, 1Na-1C-2Crandom222 and 3Na-1C2Crandom333 models. This strongly suggests the presence of $\mathrm{B}_{4} \mathrm{C}_{2}$ octahedral clusters, in agreement with ${ }^{11} \mathrm{~B}$ NMR. When combining ${ }^{11} \mathrm{~B}$ and ${ }^{23} \mathrm{Na}$ results, the presence of $\mathrm{B}_{5} \mathrm{C}$ and $\mathrm{B}_{4} \mathrm{C}_{2}$ octahedral clusters with $\mathrm{Na}$ vacancies around the latter gives the best agreement between experimental and theoretical data.

Overall, our results support a view where the as-synthesized sodium borocarbide nanocrystals encompass $\mathrm{B}_{5} \mathrm{C}$ and $\mathrm{B}_{4} \mathrm{C}_{2}$ octahedral clusters. The former are surrounded by occupied $\mathrm{Na}$ sites, where $\mathrm{Na}$ provides one electron to yield formerly $\mathrm{B}_{5} \mathrm{C}^{-}$clusters, so that the solid obeys the stoichiometry $\mathrm{NaB}_{5} \mathrm{C}$ in the short range. The environment of $\mathrm{B}_{4} \mathrm{C}_{2}$ octahedra is different as it contains $\mathrm{Na}$ vacancies, yielding the stoichiometry $\mathrm{B}_{4} \mathrm{C}_{2}$ at the short range. Both $\mathrm{B}_{5} \mathrm{C}^{-}$and $\mathrm{B}_{4} \mathrm{C}_{2}$ units meet the electron counting of 20 electrons for electronic stabilization. To our knowledge, $\mathrm{B}_{4} \mathrm{C}_{2}$ octahedral units or clusters have not been reported in inorganic solids, probably because of large strains to which they would be subjected. Their possible distortion will be studied in further work. Interestingly, the existence of $\mathrm{B}_{4} \mathrm{C}_{2}$ units has been previously suggested by Ivanovskii and Okatov who used DFT calculations to evaluate the electronic structure of $\mathrm{NaB}_{5} \mathrm{C}$ and of an hypothetical cation-empty framework built only on $\mathrm{B}_{4} \mathrm{C}_{2}$ clusters. ${ }^{48}$ These calculations suggest that such clusters associated to cation vacancies may 
occur in $\mathrm{NaB}_{5} \mathrm{C}$-based structures, in agreement with our experimental results. However, it is intriguing to note that while $\mathrm{B}_{4} \mathrm{C}_{2}$ octahedral units have not been detected in bulk compounds, our results suggest that they might occur in nanocrystals. This could be related to the ability of nanocrystals to accommodate larger strains, and then to isolate such distorted structures, which are certainly metastable.

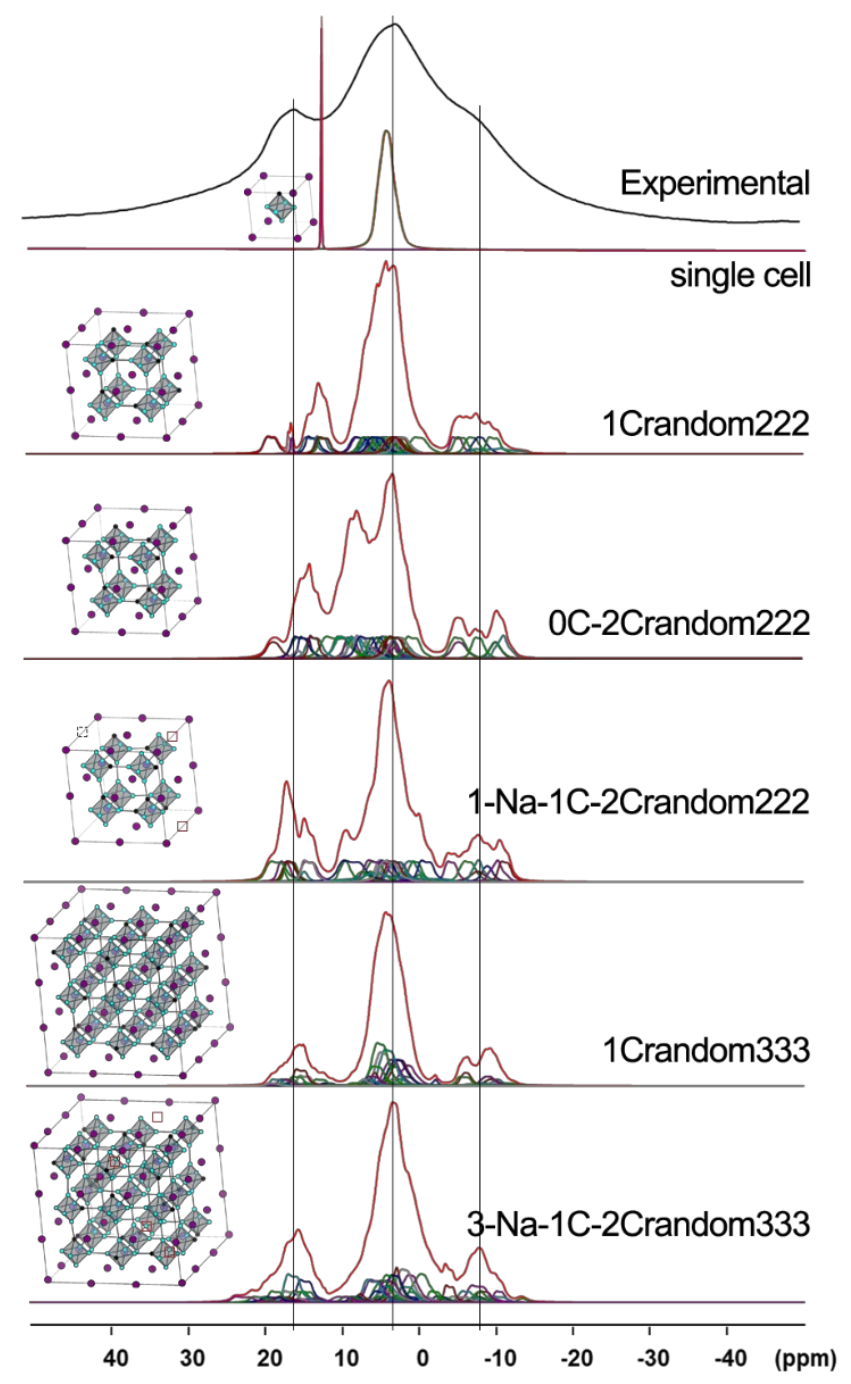

Figure 4. ${ }^{11} \mathrm{~B}$ experimental solid-state NMR spectrum of $\mathrm{NaB}_{5} \mathrm{C}$-related sodium carbaboride powder and calculated spectra for the different structural models, detailed in Figure 5. The single cell spectrum is calculated from the reported structure of $\mathrm{NaB}_{5} \mathrm{C}$, where the carbon atom in $\mathrm{B}_{5} \mathrm{C}$ octahedra is always at the same position (equivalent of a $2 \times 2 \times 2$ or a $3 \times 3 \times 3$ supercell with iso-located carbon atoms in each octahedral cluster). The three vertical lines are guides to the eye for the position of the three main features observed in the experimental spectrum. 

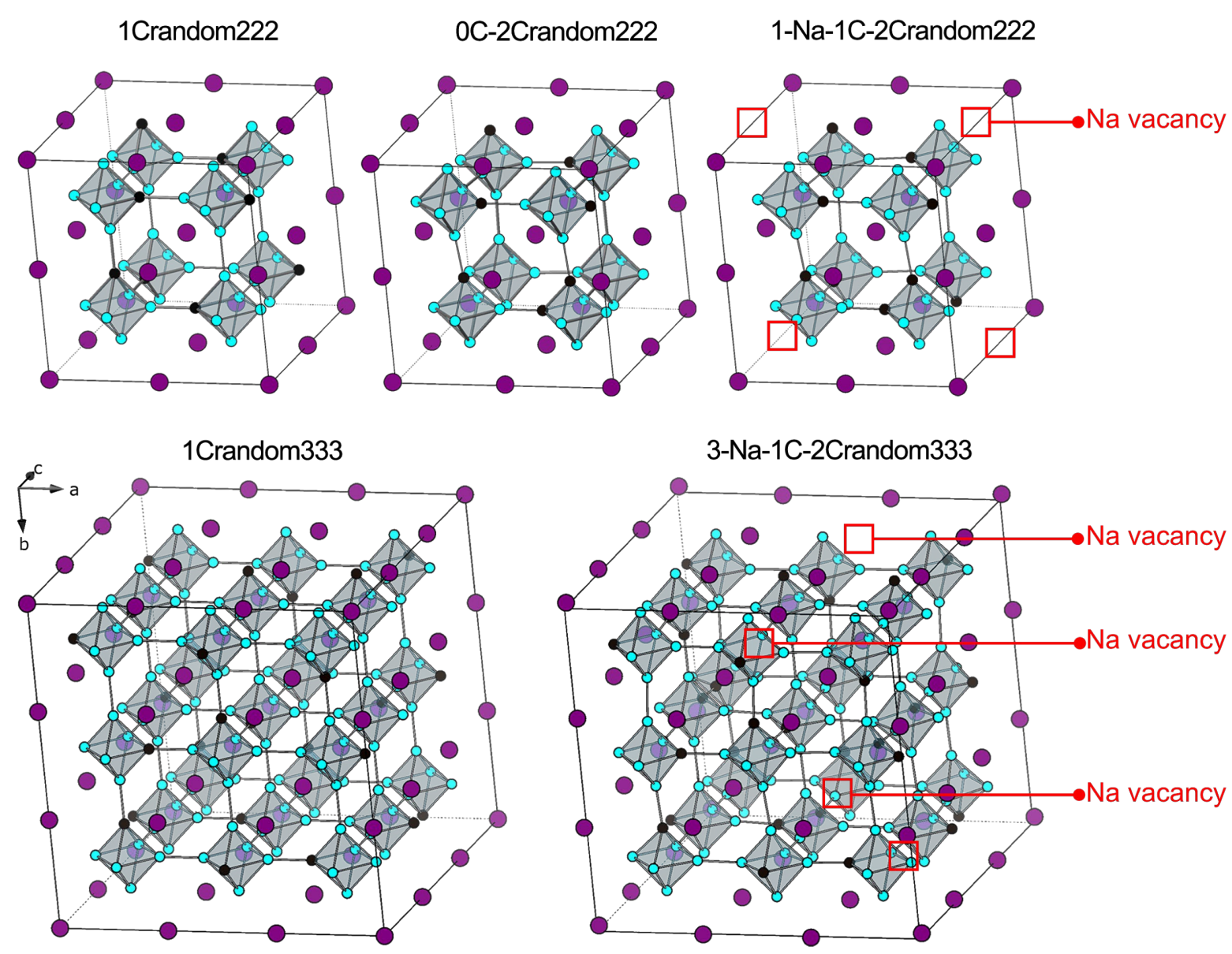

Figure 5. Structural models used to calculate the ${ }^{11}$ B NMR spectra of sodium carbaborides.

Boron, carbon and sodium atoms are in blue, black and purple, respectively. The octahedral clusters are represented in light grey. Sodium vacancies are represented with a red square.

\section{High temperature transformation}

The atom-scale mixture of boron and carbon in sodium carbaboride and the volatility of sodium might result in boron carbides upon thermal decomposition. Boron carbide, commonly known as black diamond, is an attractive material for its excelling hardness. ${ }^{49}$ Rhombohedral boron carbides (Figure 6 and Movie S2) exist as solid solutions usually presented in either its carbonpoor or its carbon-rich ideal stoichiometries: $\mathrm{B}_{13} \mathrm{C}_{2}$ (carbon content $=13$ at. $\%$ ) or $\mathrm{B}_{4} \mathrm{C}($ carbon content $=20$ at. $\%$ ), respectively. However, its solubility range further extends from 9.2 at.\% to 
21.6 at.\% in carbon. ${ }^{50}$ In its ideal stoichiometry, $\mathrm{NaB}_{5} \mathrm{C}$ contains a $\mathrm{C} /(\mathrm{B}+\mathrm{C})$ ratio of 0.17 at., while the refined formula of $\mathrm{Na}_{0.816} \mathrm{~B}_{4.816} \mathrm{C}_{1.184}$ corresponds to a ratio of 0.20 at., both within the solid solubility range for rhombohedral boron carbides. Such a broad coexistence between boron and carbon arises from the crystal structure of boron carbide, shown in Figure 6. Boron forms typical icosahedral clusters $\left(\mathrm{B}_{12}\right)$, bonded to one another by both direct covalent linkage between the polar position $\left(\mathrm{B}_{\mathrm{p}}\right)$ and also through a 3 atoms covalent chain connecting equatorial $\left(\mathrm{B}_{\mathrm{e}}\right)$ boron atoms. Both icosahedral positions and the three-atoms chains are susceptible of carbon substitution: $\mathrm{B}_{12}, \mathrm{~B}_{11} \mathrm{C}, \mathrm{B}_{10} \mathrm{C}_{2}$, and $\mathrm{B}_{9} \mathrm{C}_{3}$ icosahedra and $\mathrm{CCC}, \mathrm{CBC}, \mathrm{CCB}, \mathrm{CBB}, \mathrm{BCB}$, and BBB chains have been suggested in the literature..$^{51,52}$
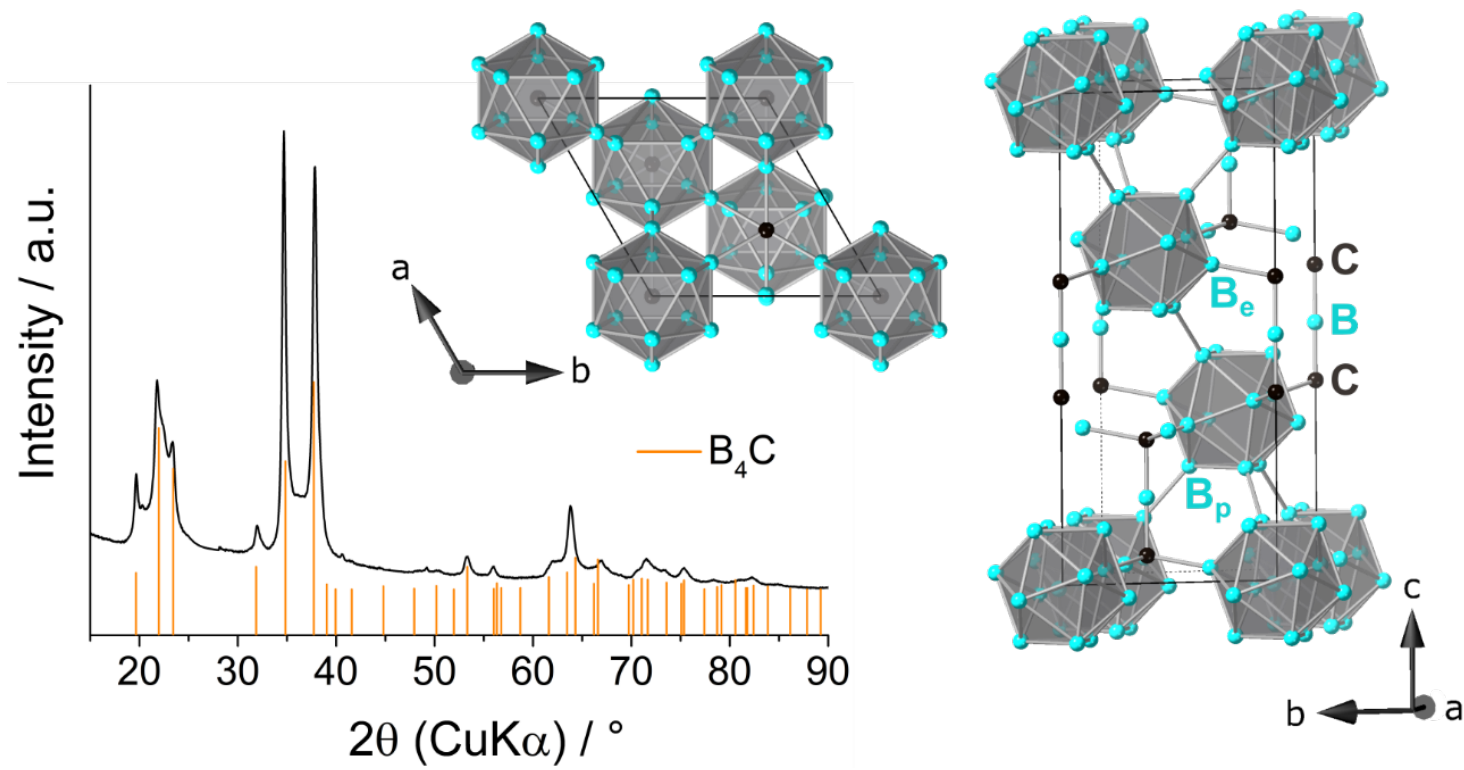

Figure 6. Powder XRD pattern of the powder obtained after calcination of sodium carbaboride nanocrystals. The reference pattern corresponds to rhombohedral $\mathrm{B}_{4} \mathrm{C}$-type boron carbide. Two different views of a corresponding ideal crystal structure are displayed.

We have then evaluated the thermal behavior of the molten salt-derived sodium carbaboride nanocrystals by calcining the powders under argon flow at $1200{ }^{\circ} \mathrm{C}$. Upon heat treatment, the solid is thoroughly washed and analyzed. The X-ray diffraction pattern of the product is consistent with the expected one for boron carbide (Figure 6). TEM images of the resulting powder show well faceted nanoparticles of average edge size $9.9 \mathrm{~nm}$ according to a 
lognormal fit of the edge length distribution of 100 nanoparticles (Figure 7A). High resolution

TEM (Figure 7B) shows lattice fringes with distances characteristic of rhombohedral boron carbide crystal planes. As mentioned before, the complex covalent network of boron carbide yields high Vickers hardness values above the superhardness threshold (40 GPa). Further investigation of the impact of nanostructuration on the properties of boron carbide are underway.

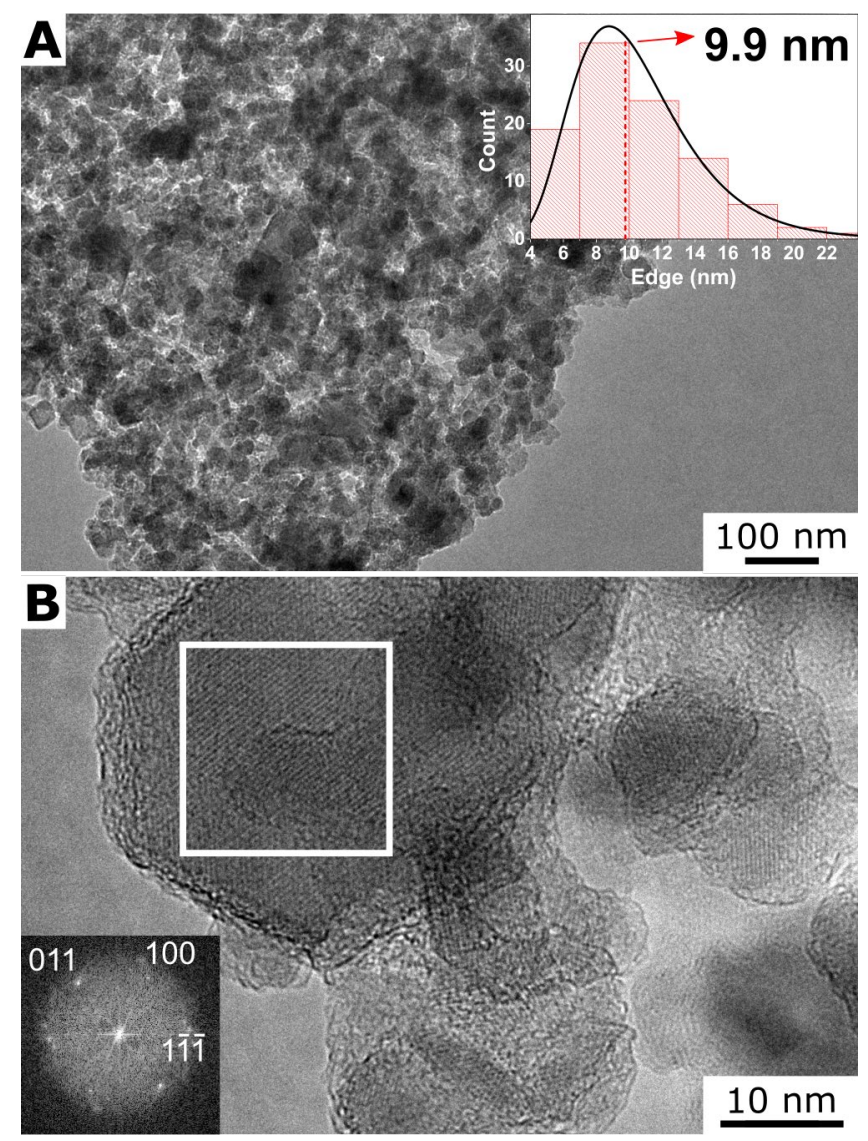

Figure 7. (A) TEM and (B) HRTEM images of boron carbide nanocrystals obtained by the decomposition of molten salt-derived sodium carbaboride nanocrystals. The inset in A shows the size distribution fitted with a lognormal function. The inset in B is a Fast Fourier Transform of the region marked with a white square. The reflexions are indexed along the rhombohedral boron carbide structure.

\section{Conclusion}

In conclusion, by using liquid-phase synthesis in molten salts, we have designed sodium carbaboride nanocrystals. These nanocrystals deviate from the ideal stoichiometry $\mathrm{NaB}_{5} \mathrm{C}$ that 
was reported up to now for the bulk compound. They show sodium vacancies which seem to be compensated by carbon over-stoichiometry in the octahedral units. As the model we propose is built on full octahedral units, the nanocrystals still obey the electron counting rule for full stabilization of an octahedral framework, but besides $\mathrm{B}_{5} \mathrm{C}$ units, they also encompass $\mathrm{B}_{4} \mathrm{C}_{2}$ octahedral units, which to our knowledge have not been reported before in bulk inorganic compounds. This emerging diversity in octahedral structural building units in boron-based nano-objects might have a significant impact on the electronic and ionic conduction properties of these nanocrystals. Further study of the local structure around these units is then needed and will be addressed in a further work. More generally, widening the scope of covalent building blocks in boron-rich nano-objects compared to bulk compounds raises the question of the possible emergence of new boron-rich solids at the nanoscale, and then of possibly new properties, an issue that will deserve more efforts in the future. Finally, we provide the first evidence that such alkali-based nanocrystals can be used as efficient precursors to other boronrich solids, especially boron carbides. These materials will require more in depth study but they already show that the reactivity of boron-rich nanoparticles may be used to target further complex covalent solids and materials.

\section{Supporting information}

The Supporting Information is available free of charge at https://pubs.acs.org/doi/xxx: Table S1 summarizing reported syntheses of sodium and potassium carbaborides, detailed XRD characterization in Figure S1, Raman, solid state ${ }^{1} \mathrm{H}$ NMR and X-ray photoelectron spectroscopic data in Figures S2, S3 and S4, respectively, XPS quantification in Table S2. details of ${ }^{11} \mathrm{~B}$ and ${ }^{23} \mathrm{Na}$ solid state NMR calculations in Figures S5 and S6, respectively, with Tables S3 to S10. 


\section{Acknowledgements}

SD and FI thank the French Ministry for Research (MESRI) for funding. SD, YLG and DP thank the CNRS for funding through the Energie cell. NMR spectroscopic calculations were performed using HPC resources from GENCI-IDRIS (Grant 097535). YS acknowledges funding from the China Scholarship Council. NMR and XPS facilities belong to Institut des Matériaux de Paris Centre. The authors thank Antoine Miche for XPS measurements.

\section{References}

(1) Albert, B.; Hillebrecht, H. Boron: Elementary Challenge for Experimenters and Theoreticians. Angew. Chem. Int. Ed. 2009, 48, 8640-8668. https://doi.org/10.1002/anie.200903246.

(2) Akopov, G.; Yeung, M. T.; Kaner, R. B. Rediscovering the Crystal Chemistry of Borides. Adv. Mater. 2017, 1604506. https://doi.org/10.1002/adma.201604506.

(3) Mattox, T. M.; Agrawal, A.; Milliron, D. J. Low Temperature Synthesis and Surface Plasmon Resonance of Colloidal Lanthanum Hexaboride ( $\left.\mathrm{LaB}_{6}\right)$ Nanocrystals. Chem. Mater. 2015, 27, 6620-6624. https://doi.org/10.1021/acs.chemmater.5b02297.

(4) Li, L.; Sun, K.; Kurdak, C.; Allen, J. W. Emergent Mystery in the Kondo Insulator Samarium Hexaboride. Nat. Rev. Phys. 2020, 2, 463-479. https://doi.org/10.1038/s42254-020-0210-8.

(5) Longuet-Higgins, H. C.; Roberts, M. de V. The Electronic Structure of the Borides MB 6 . Proc. R. Soc. A Math. Phys. Eng. Sci. 1954, 224, 336-347. https://doi.org/10.1098/rspa.1954.0162.

(6) Schmitt, K.; Stu, C.; Ripplinger, H.; Albert, B. Crystal and Electronic Structure of $\mathrm{BaB}_{6}$ in Comparison with $\mathrm{CaB}_{6}$ and Molecular $\left[\mathrm{B}_{6} \mathrm{H}_{6}\right]^{2-}$. Solid State Sci. 2001, 3, 321327. https://doi.org/10.1016/S1293-2558(00)01091-8.

(7) Wade, K. The Structural Significance of the Number of Skeletal Bonding ElectronPairs in Carboranes, the Higher Boranes and Borane Anions, and Various TransitionMetal Carbonyl Cluster Compounds. J. Chem. Soc. D Chem. Commun. 1971, 15, 792793. https://doi.org/10.1039/C29710000792.

(8) Mingos, D. M. P. A General Theory for Cluster and Ring Compounds of the Main Group and Transition Elements. Nat. Phys. Sci. 1972, 236, 99-102. https://doi.org/10.1038/physci236099a0. 
(9) Jemmis, E. D.; Balakrishnarajan, M. M.; Pancharatna, P. D. A Unifying ElectronCounting Rule for Macropolyhedral Boranes, Metallaboranes, and Metallocenes. $J$. Am. Chem. Soc. 2001, 123, 4313-4323. https://doi.org/10.1021/ja003233z.

(10) Zintl, E. Intermetallische Verbindungen. Angew. Chem. 1939, 52, 1-6. https://doi.org/10.1002/ange.19390520102.

(11) Schäfer, H.; Eisenmann, B.; Müller, W. Zintl Phases: Transitions between Metallic and Ionic Bonding. Angew. Chem. Int. Ed. 1973, 12, 694-712. https://doi.org/https://doi.org/10.1002/anie.197306941.

(12) Mair, G.; von Schnering, H. G.; Wörle, M.; Nesper, R. Dilithium Hexaboride, Li2B6. Zeitschrift für Anorg. und Allg. Chemie 1999, 625, 1207-1211. https://doi.org/10.1002/(SICI)1521-3749(199907)625:7<1207::AIDZAAC1207>3.0.CO;2-9.

(13) Naslain, R.; Etourneau, J. L'hexaborure de Potassium. C. R. Acad. Sc. 1966, 263, 484.

(14) Ammar, A.; Ménétrier, M.; Villesuzanne, A.; Matar, S.; Chevalier, B.; Etourneau, J.; Villeneuve, G.; Rodríguez-Carvajal, J.; Koo, H. J.; Smirnov, A. I.; Whangbo, M. H. Investigation of the Electronic and Structural Properties of Potassium Hexaboride, $\mathrm{KB}_{6}$, by Transport, Magnetic Susceptibility, EPR, and NMR Measurements, Temperature-Dependent Crystal Structure Determination, and Electronic Band Structure Calculations. Inorg. Chem. 2004, 43, 4974-4987. https://doi.org/10.1021/ic049444c.

(15) Albert, B.; Schmitt, K. $\mathrm{NaB}_{5} \mathrm{C}$ : Carbon Insertion into a Three-Dimensional Framework of Boron Octahedra Leads to Electron-Precise Cubic Carbaborides. Chem. Commun. 1998, 21, 2373-2374. https://doi.org/10.1039/a806994h.

(16) Albert, B.; Schmitt, K. New Boron-Rich Materials: Cubic Carbaborides of Sodium and Potassium. Chem. Mater. 1999, 11, 3406-3409. https://doi.org/10.1021/cm991130d.

(17) Soriano, R. B.; Arachchige, I. U.; Malliakas, C. D.; Wu, J.; Kanatzidis, M. G. Nanoscale Stabilization of New Phases in the PbTe-Sb $\mathrm{Te}_{3}$ System: $\mathrm{Pb}_{\mathrm{m}} \mathrm{Sb}_{2 \mathrm{n}} \mathrm{Te}_{\mathrm{m}+3 \mathrm{n}}$ Nanocrystals. J. Am. Chem. Soc. 2013, 135, 768-774.

https://doi.org/10.1021/ja309626q.

(18) Baitinger, M.; Böhme, B.; Ormeci, A.; Grin, Y. Solid State Chemistry of Clathrate Phases: Crystal Structure, Chemical Bonding and Preparation Routes. In The Physics and Chemistry of Inorganic Clathrates; Nolas, G. S., Ed.; Springer Science \& Business Media: Dordrecht, 2014; p 332. https://doi.org/10.1007/978-94-017-9127-4.

(19) Thévenot, F. Boron Carbide-A Comprehensive Review. J. Eur. Ceram. Soc. 1990, 6, 205-225. https://doi.org/10.1016/0955-2219(90)90048-K.

(20) Liu, J.; Wen, S.; Hou, Y.; Zuo, F.; Beran, G. J. O.; Feng, P. Boron Carbides as Efficient, Metal-Free, Visible-Light-Responsive Photocatalysts. Angew. Chem. Int. Ed. 2013, 52, 3241-3245. https://doi.org/10.1002/anie.201209363.

(21) Morito, H.; Anzai, J.; Kimura, T.; Yamane, H. Synthesis of $\mathrm{NaB}_{5} \mathrm{C}$ Bulk Ceramics by Reaction Sintering. Solid State Sci. 2015, 47, 39-42. 
https://doi.org/10.1016/j.solidstatesciences.2015.03.013.

(22) Morito, H.; Kimura, T.; Yamane, $\mathrm{H}$. NaB $\mathrm{Na}_{5} \mathrm{C}-\mathrm{B}_{5} / \mathrm{C}$ Composite Ceramics Prepared by Reaction Sintering in Na Vapor. J. Am. Ceram. Soc. 2016, 99, 2422-2427. https://doi.org/10.1111/jace.14204.

(23) Carenco, S.; Portehault, D.; Boissière, C.; Mézailles, N.; Sanchez, C. Nanoscaled Metal Borides and Phosphides: Recent Developments and Perspectives. Chem. Rev. 2013, 113, 7981-8065. https://doi.org/10.1021/cr400020d.

(24) Portehault, D.; Delacroix, S.; Gouget, G.; Grosjean, R.; Chan-Chang, T.-H.-C. Beyond the Compositional Threshold of Nanoparticle-Based Materials. Acc. Chem. Res. 2018, 51, 930-939. https://doi.org/10.1021/acs.accounts.7b00429.

(25) Portehault, D.; Devi, S.; Beaunier, P.; Gervais, C.; Giordano, C.; Sanchez, C.; Antonietti, M. A General Solution Route toward Metal Boride Nanocrystals. Angew. Chem. Int. Ed. 2011, 50, 3262-3265. https://doi.org/10.1002/anie.201006810.

(26) Gouget, G.; Beaunier, P.; Portehault, D.; Sanchez, C. New Route toward Nanosized Crystalline Metal Borides with Tunable Stoichiometry and Variable Morphologies. Faraday Discuss. 2016, 191, 511-525. https://doi.org/10.1039/C6FD00053C

(27) Terlan, B.; Levin, A. A.; Börrnert, F.; Zeisner, J.; Kataev, V.; Schmidt, M.; Eychmueller, A. A Size-Dependent Analysis of the Structural, Surface, Colloidal, and Thermal Properties of $\mathrm{Ti}_{1-\mathrm{x}} \mathrm{B}_{2}(\mathrm{x}=0.03-0.08)$ Nanoparticles. Eur. J. Inorg. Chem. 2016, 2016, 3460-3468. https://doi.org/10.1002/ejic.201600315.

(28) Terlan, B.; Levin, A.; Börrnert, F.; Simon, F.; Oschatz, M.; Schmidt, M.; Cardoso-Gil, R.; Lorenz, T.; Baburin, I.; Joswig, J.-O.; Eychmueller, A. Effect of Surface Properties on the Microstructure, Thermal and Colloidal Stability of $\mathrm{VB}_{2}$ Nanoparticles. Chem. Mater. 2015, 27, 5106-5115. https://doi.org/10.1021/acs.chemmater.5b01856.

(29) Ma, J. L.; Li, N.; Zhang, Q.; Zhang, X. B.; Wang, J.; Li, K.; Hao, X. F.; Yan, J. M. Synthesis of Porous and Metallic CoB Nanosheets towards a Highly Efficient Electrocatalyst for Rechargeable $\mathrm{Na}_{-} \mathrm{O}_{2}$ Batteries. Energy Environ. Sci. 2018, 11, 2833-2838. https://doi.org/10.1039/c8ee01472h.

(30) Yu, Y.; Wang, S.; Li, W.; Chen, Z. Low Temperature Synthesis of LaB 6 Nanoparticles by a Molten Salt Route. Powder Technol. 2018, 323, 203-207. https://doi.org/10.1016/j.powtec.2017.09.049.

(31) Yu, Y.; Wang, S.; Li, W.; Chen, H.; Chen, Z. Synthesis of Single-Crystalline Lanthanum Hexaboride Nanocubes by a Low Temperature Molten Salt Method. Mater. Chem. Phys. 2018, 207, 325-329. https://doi.org/10.1016/j.matchemphys.2017.12.081.

(32) Groome, C.; Roh, I.; Mattox, T. M.; Urban, J. J. Effects of Size and Structural Defects on the Vibrational Properties of Lanthanum Hexaboride Nanocrystals. ACS Omega 2017, 2, 2248-2254. https://doi.org/10.1021/acsomega.7b00263.

(33) Gouget, G.; Debecker, D. P.; Kim, A.; Olivieri, G.; Gallet, J.-J.; Bournel, F.; Thomas, C.; Ersen, O.; Moldovan, S.; Sanchez, C.; Carenco, S.; Portehault, D. In Situ Solid-Gas 
Reactivity of Nanoscaled Metal Borides from Molten Salt Synthesis. Inorg. Chem. 2017, 56, 9225-9234. https://doi.org/10.1021/acs.inorgchem.7b01279.

(34) Delacroix, S.; Le Godec, Y.; Coelho-Diogo, C.; Gervais, C.; Génois, I.; Le Griel, P.; Portehault, D. Synthesis in Molten Salts and Characterization of $\mathrm{Li}_{6} \mathrm{~B}_{18}\left(\mathrm{Li}_{2} \mathrm{O}\right)_{\mathrm{x}}$ Nanoparticles. Inorg. Chem. 2020, 18, 2-7.

https://doi.org/10.1021/acs.inorgchem.0c01694.

(35) Rodriguez-Carvajal, J. FullProf Suite; All the Programs Can Be Obtained from: Http://Www.Ill.Eu/Sites/Fullprof. Laboratoire Léon Brillouin, CEA: Saclay, France.

(36) Kresse, G.; Hafner, J. Ab Initio Molecular-Dynamics Simulation of the Liquid-Metal-Amorphous-Semiconductor Transition in Germanium. Phys. Rev. B 1994, 49, 1425114269. https://doi.org/10.1103/PhysRevB.49.14251.

(37) Giannozzi, P.; Baroni, S.; Bonini, N.; Calandra, M.; Car, R.; Cavazzoni, C.; Ceresoli, D.; Chiarotti, G. L.; Cococcioni, M.; Dabo, I.; Dal Corso, A.; de Gironcoli, S.; Fabris, S.; Fratesi, G.; Gebauer, R.; Gerstmann, U.; Gougoussis, C.; Kokalj, A.; Lazzeri, M.; Martin-Samos, L.; Marzari, N.; Mauri, F.; Mazzarello, R.; Paolini, S.; Pasquarello, A.; Paulatto, L.; Sbraccia, C.; Scandolo, S.; Sclauzero, G.; Seitsonen, A. P.; Smogunov, A.; Umari, P.; Wentzcovitch, R. M. QUANTUM ESPRESSO: A Modular and OpenSource Software Project for Quantum Simulations of Materials. J. Phys. Condens. Matter 2009, 21, 395502. https://doi.org/10.1088/0953-8984/21/39/395502.

(38) Perdew, J. P.; Burke, K.; Ernzerhof, M. Generalized Gradient Approximation Made Simple. Phys. Rev. Lett. 1996, 77, 3865-3868.

https://doi.org/10.1103/physrevlett.77.3865

(39) Troullier, N.; Martins, J. L. Efficient Pseudopotentials for Plane-Wave Calculations. Phys. Rev. B 1991, 43, 1993-2006. https://doi.org/10.1103/PhysRevB.43.1993

(40) Kleinman, L.; Bylander, D. Efficacious Form for Model Pseudopotentials. Phys. Rev. Lett. 1982, 48, 1425. https://doi.org/10.1103/PhysRevLett.48.1425

(41) Pickard, C.; Mauri, F. All-Electron Magnetic Response with Pseudopotentials: NMR Chemical Shifts. Phys. Rev. B 2001, 63, 245101. https://doi.org/10.1103/PhysRevB.63.245101

(42) Mayen, L.; Jensen, N. D.; Desbord, M.; Laurencin, D.; Gervais, C.; Bonhomme, C.; Smith, M. E.; Porcher, F.; Elkaim, E.; Charvillat, C.; Gras, P.; Rey, C.; Soulié, J.; Combes, C. Advances in the Synthesis and Structure of $\alpha$-Canaphite: A Multitool and Multiscale Study. CrystEngComm 2020, 22, 3130-3143. https://doi.org/10.1039/D0CE00132E.

(43) Pyykkö, P. Year-2008 Nuclear Quadrupole Moments. Mol. Phys. 2008, 106, 19651974. https://doi.org/10.1080/00268970802018367

(44) Massiot, D.; Fayon, F.; Capron, M.; King, I.; Le Calvé, S.; Alonso, B.; Durand, J. O.; Bujoli, B.; Gan, Z.; Hoatson, G. Modelling One- and Two-Dimensional Solid-State NMR Spectra. Magn. Reson. Chem. 2002, 40, 70-76. https://doi.org/10.1002/mrc.984.

(45) Zhang, S.; Lu, W.; Wang, C.; Shen, Q.; Zhang, L. Stoichiometric Controlling of Boron 
Carbide Thin Films by Using Boron-Carbon Dual-Targets. Appl. Phys. Lett. 2012, 101, 141602. https://doi.org/10.1063/1.4754628.

(46) Kirkpatrick, R. J.; Aselage, T.; Phillips, B. L.; Montez, B. ${ }^{11}$ B and ${ }^{13} \mathrm{C}$ NMR Spectroscopy of Boron Carbides. AIP Conf. Proc. 1991, 261-270.

https://doi.org/10.1063/1.40836.

(47) Pallier, C.; Leyssale, J.-M.; Truflandier, L. A.; Bui, A. T.; Weisbecker, P.; Gervais, C.; Fischer, H. E.; Sirotti, F.; Teyssandier, F.; Chollon, G. Structure of an Amorphous Boron Carbide Film: An Experimental and Computational Approach. Chem. Mater. 2013, 25, 2618-2629. https://doi.org/10.1021/cm400847t.

(48) Ivanovskii, A. L.; Okatov, S. V. The Electronic Structure of the New Cubic Carbaboride $\mathrm{NaB}_{5} \mathrm{C}$ as Compared to $\mathrm{CaB}_{6}$ and " $\mathrm{B}_{4} \mathrm{C}_{2}$ " by the Full-Potential LMTO Method. Mendeleev Commun. 2001, 11, 8-9. https://doi.org/10.1070/mc2001v011n01abeh001393.

(49) Domnich, V.; Gogotsi, Y.; Trenary, M.; Tanaka, T. Nanoindentation and Raman Spectroscopy Studies of Boron Carbide Single Crystals. Appl. Phys. Lett. 2002, 81, 3783-3785. https://doi.org/10.1063/1.1521580.

(50) Beauvy, M. Stoichiometric Limits of Carbon-Rich Boron Carbide Phases. J. Less Common Met. 1983, 90, 169-175. https://doi.org/https://doi.org/10.1016/00225088(83)90067-X.

(51) Domnich, V.; Reynaud, S.; Haber, R. a.; Chhowalla, M. Boron Carbide: Structure, Properties, and Stability under Stress. J. Am. Ceram. Soc. 2011, 94, 3605-3628. https://doi.org/10.1111/j.1551-2916.2011.04865.x.

(52) Rasim, K.; Ramlau, R.; Leithe-Jasper, A.; Mori, T.; Burkhardt, U.; Borrmann, H.; Schnelle, W.; Carbogno, C.; Scheffler, M.; Grin, Y. Local Atomic Arrangements and Band Structure of Boron Carbide. Angew. Chem. Int. Ed. 2018, 57, 6130-6135. https://doi.org/https://doi.org/10.1002/anie.201800804. 


\section{Table of content graphic}

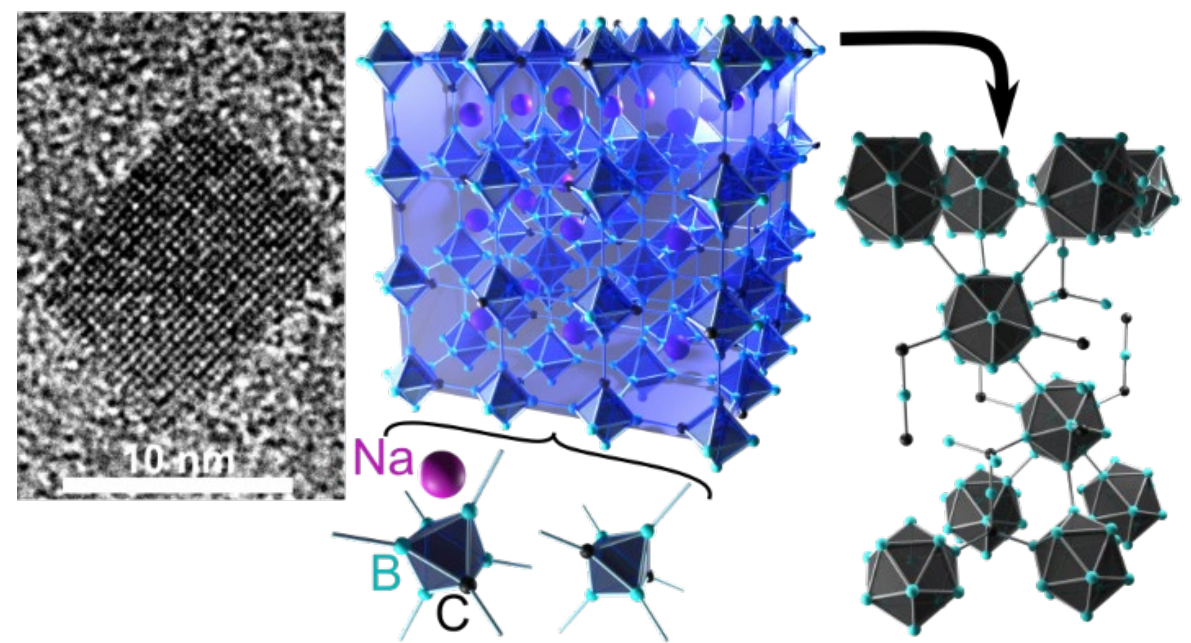

\section{Table of content synopsis}

Sodium borocarbide nanocrystals synthesized in molten salts provide the opportunity to explore for the first time the reactivity of these cluster-based solids. They also enable addressing the fundamental question about how electron counting rules in boron-rich solids apply in nanocrystals with stoichiometries that deviate from the previously known bulk cases. We show that these nanocrystals evolve towards boron carbide upon heating and that they fulfill electron counting rules by accommodating alternative cluster compositions. 


\section{Supporting information}

\section{Electron precise sodium carbaboride nanocrystals}

\section{from molten salts: single sources to boron carbides}

Simon Delacroix, ${ }^{1,2}$ Fernando Igoa, ${ }^{1,2}$ Yang Song, ${ }^{1}$ Yann Le Godec, ${ }^{2, *}$ Cristina CoelhoDiogo, ${ }^{3}$ Christel Gervais, ${ }^{1}$ Gwenaelle Rousse,${ }^{4}$ David Portehault ${ }^{1, *}$

${ }^{1}$ Sorbonne Université, CNRS, Collège de France, Laboratoire de Chimie de la Matière Condensée de Paris (CMCP), 4 place Jussieu, F-75005, Paris, France

${ }^{2}$ Sorbonne Université, CNRS, MNHN, IRD, Institut de Minéralogie, de Physique des Matériaux et de Cosmochimie (IMPMC), 4 place Jussieu, F-75005, Paris, France

${ }^{3}$ Sorbonne Université, CNRS, Institut des Matériaux de Paris Centre (IMPC), 4 place Jussieu, F-75005, Paris, France

${ }^{4}$ Collège de France, Sorbonne Université, Chimie du Solide et de l'Energie (CSE), 75231

Paris Cedex 05, France

*Corresponding authors:

david.portehault@sorbonne-universite.fr

yann.le_godec@sorbonne-universite.fr 
Table S1. Synthesis conditions of alkali carbaborides $\mathrm{NaB}_{5} \mathrm{C}$ and $\mathrm{KB}_{5} \mathrm{C}$ reported in the literature. Numbered references are those of the main text.

\begin{tabular}{|c|c|c|c|c|}
\hline Compound & Time (h) & Temperature $\left({ }^{\circ} \mathrm{C}\right)$ & Precursors & Method \\
\hline $\mathrm{NaB}_{5} \mathrm{C}^{15}$ & 2 & 1050 & $\mathrm{Na}, \mathrm{B}, \mathrm{C}_{(\mathrm{gr})}$ & Sealed vessel \\
\hline $\mathrm{NaB}_{5} \mathrm{C}^{21,22}$ & 24 & 900 & $\mathrm{Na}, \mathrm{B}, \mathrm{C}_{(\mathrm{am})}$ & $\begin{array}{c}\text { Na flux in } \\
\text { sealed vessel }\end{array}$ \\
\hline $\mathrm{KB}_{5} \mathrm{C}^{51}$ & 16 & 1100 & $\mathrm{~K}, \mathrm{~B}, \mathrm{C}_{(\mathrm{gr})}$ & $\begin{array}{c}\text { Sealed vessel } \\
\text { NaB }\end{array}$ \\
\hline
\end{tabular}



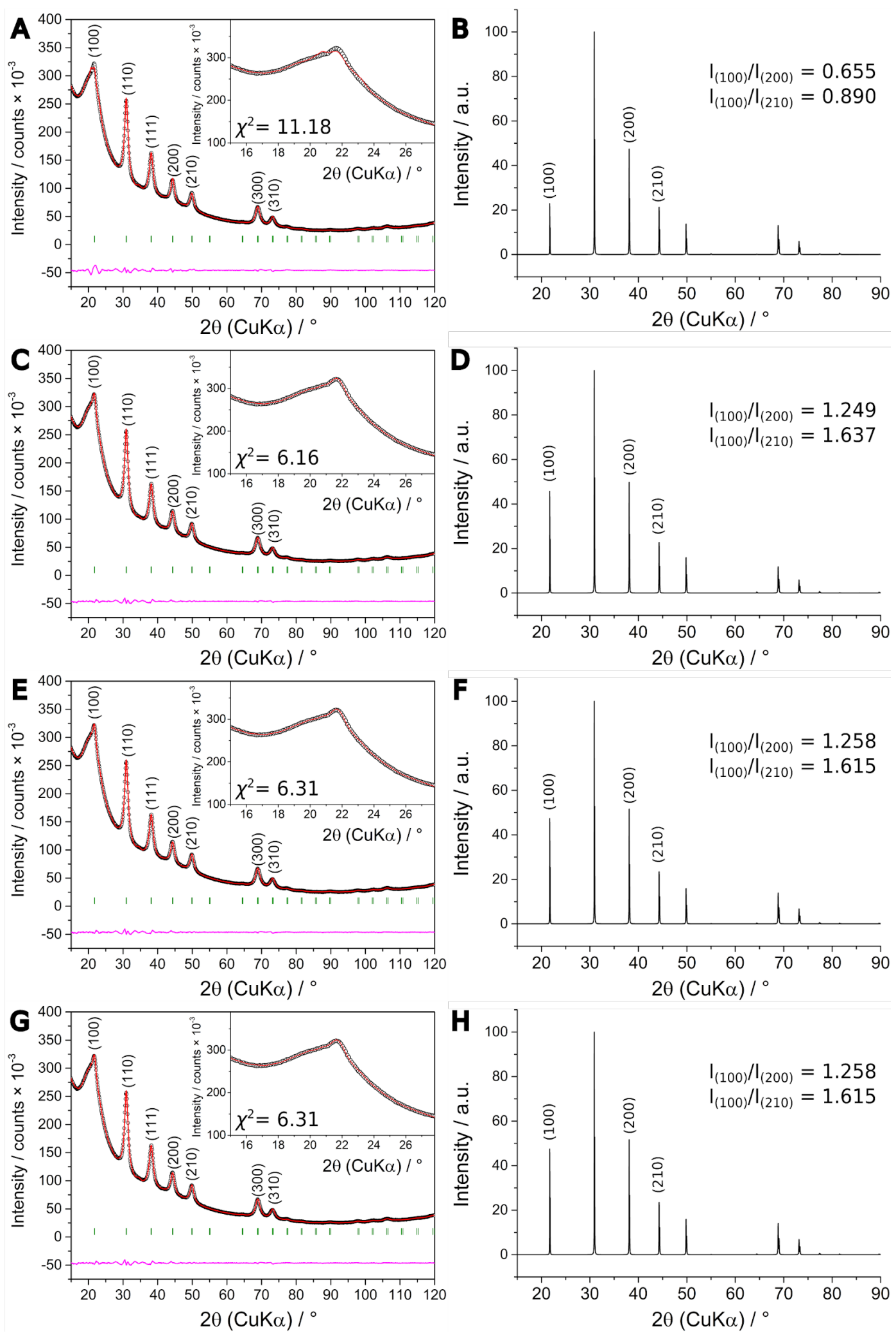

Figure S1. Consecutive Rietveld refinement of $\mathrm{NaB}_{5} \mathrm{C}$. (A) No occupation refinement. (B) Simulated XRD powder diffractogram from model considered in (A). (C) Model I, B to C ratio refinement. (D) Simulated XRD powder diffractogram from model considered in (C). (E) Model II, Na occupation refinement. (F) Simulated XRD powder diffractogram from model considered in (E). (G) Model III, occupancies refined restrained to the $\mathrm{Na}_{1-\mathrm{x}} \mathrm{B}_{5-\mathrm{x}} \mathrm{C}_{1+\mathrm{x}}$. formula. $(H)$ Simulated XRD powder diffractogram from model considered in $(G)$. 
Table S2. Crystallographic data of sodium borocarbide obtained by refinement of the structure from the X-Ray powder diffraction data at room temperature, according to model III (Figure S1 $\mathrm{G}-\mathrm{H})$.

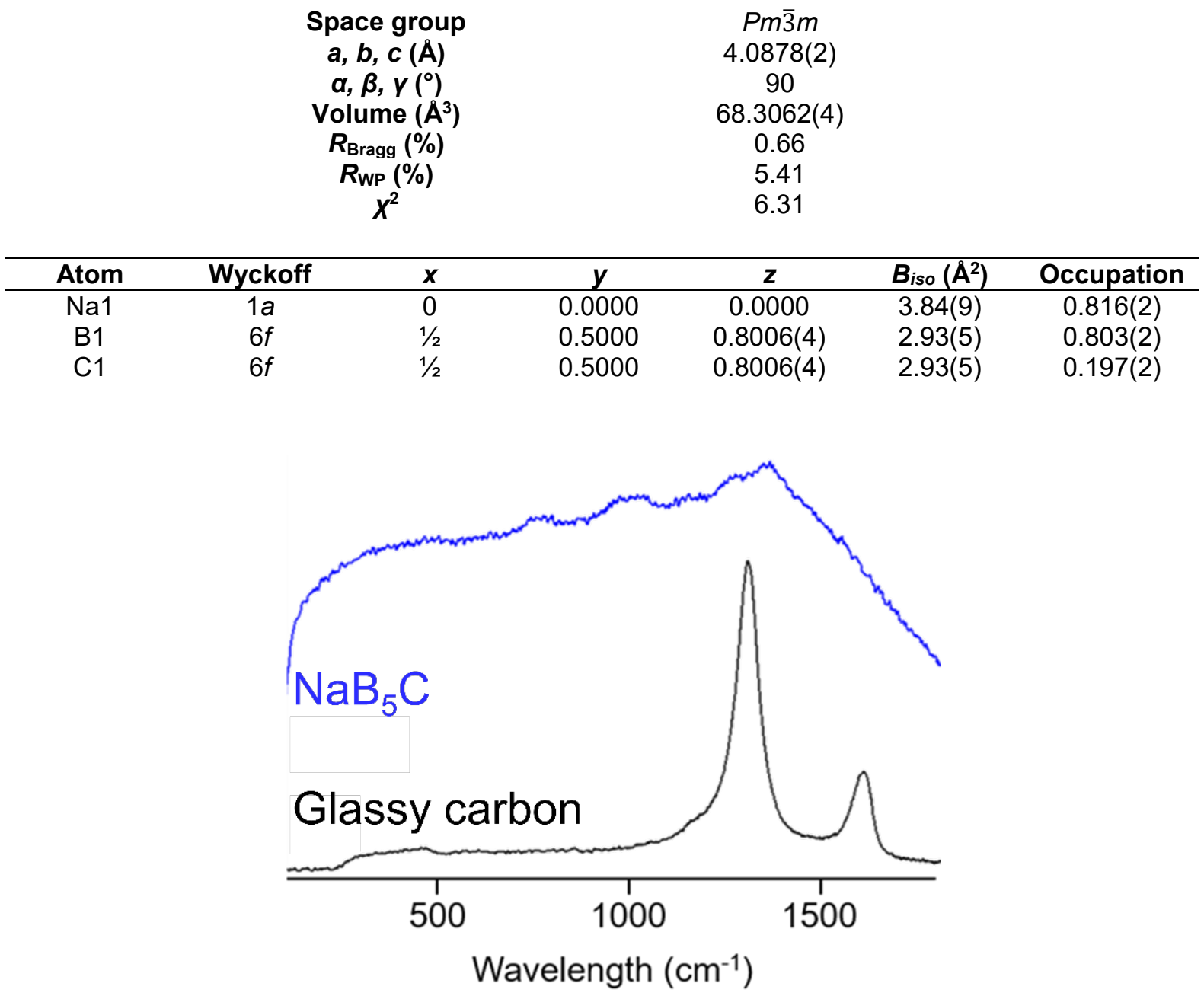

Figure S2. Raman spectra of sodium borocarbide nanocrystals (blue). The spectrum of glassy carbon is given as a reference (black), showing the two typical bands of disordered carbon with graphitic domains.

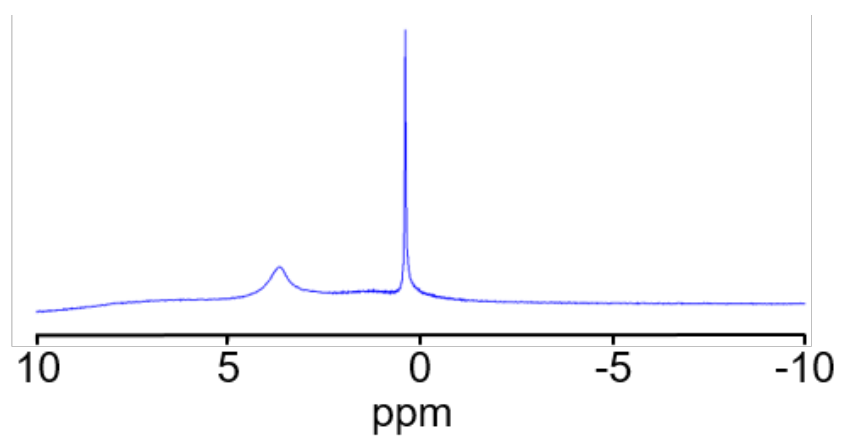

Figure S3. Solid state ${ }^{1} \mathrm{H}$ NMR spectrum of sodium borocarbide nanocrystals. 

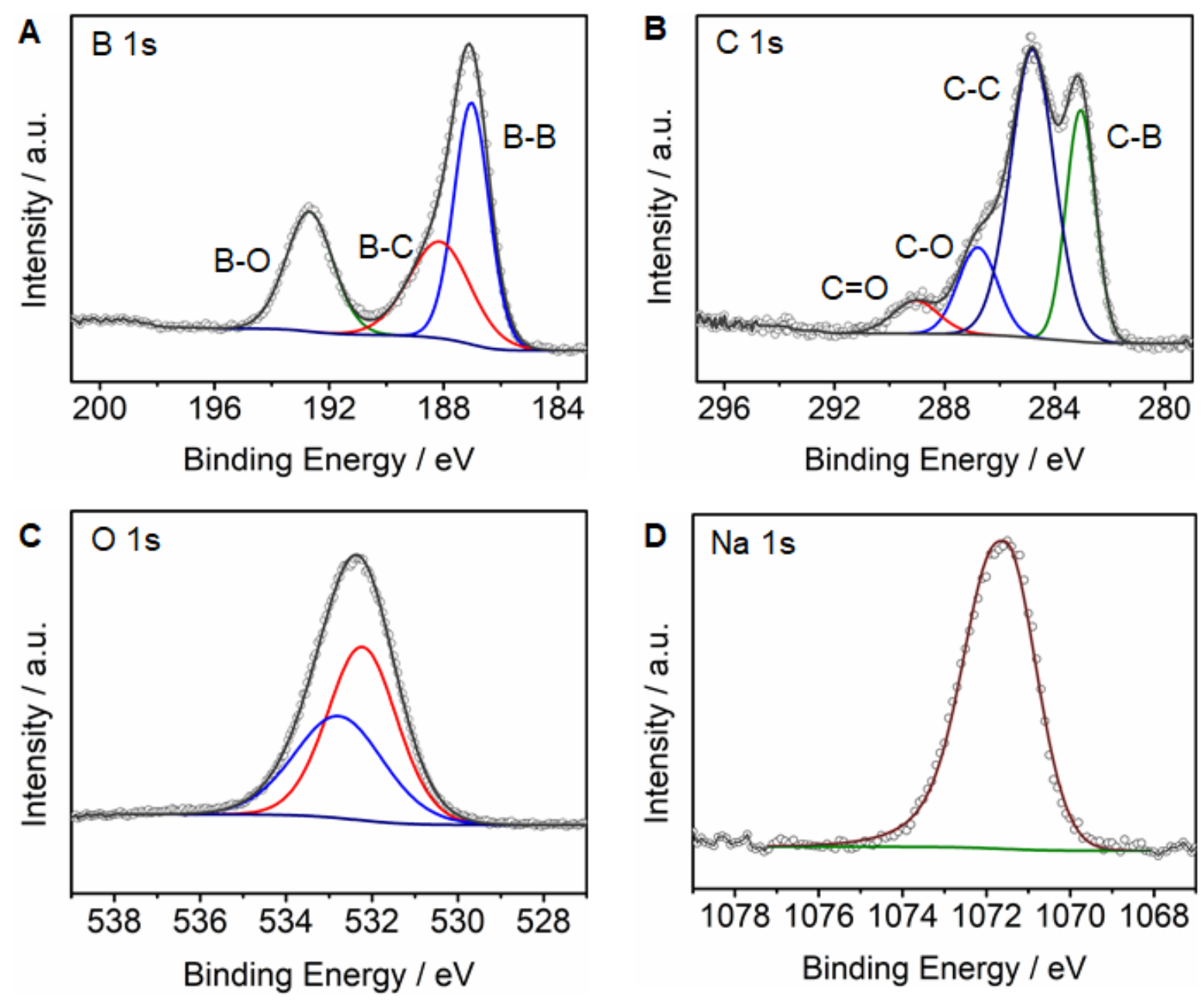

Figure S4. X ray photoelectron spectra of sodium carbaboride nanocrystals: (A) B 1s region, (B) $\mathrm{C} 1 \mathrm{~s}$ region, (C) $\mathrm{O} 1 \mathrm{~s}$ region, (D) $\mathrm{Na} 1 \mathrm{~s}$ region

\section{XPS data quantification}

Composition quantification of the sample was done with the software Thermo Avantage(C) This simplified calculation assumed that all elements are homogeneously distributed on depth. In order to yield a consistent approximation quantification, several factors were taken into account to normalize the peak area, including the sensitivity factor (SF), instrument transmission function (TXFN), and energy compensation factor (ECF). In this work, the SF was chosen with ALSCOF peak library, and the ECF was evaluated through the TPP-2M method, in order to calculate the inelastic mean free paths (IMFP). From the quantification results based on XPS data (Table S1), the overall B/C ratio is 3.2. This ratio accounts for contamination carbon and structural carbon. Because contamination cannot be avoided with the high surface area of the material, the carbon content within the nanocrystals cannot be evaluated exactly. A similar effect has been observed when evaluating the $\mathrm{B} / \mathrm{C}$ ratio by STEMEELS on a holey silica grid, which yielded a similar value. 
Table S3. XPS quantification table.

\begin{tabular}{|c|c|c|c|}
\hline \multicolumn{2}{|c|}{ Deconvoluted peaks } & \multirow{2}{*}{$\begin{array}{r}\text { BE }(\mathrm{eV}) \\
187.02\end{array}$} & \multirow{2}{*}{$\begin{array}{c}\text { Relative ratio (at.\%) } \\
29\end{array}$} \\
\hline B 1s & B-B & & \\
\hline & $B-C$ & 188.13 & 20 \\
\hline & $\mathrm{B}-\mathrm{O}$ & 192.68 & 19 \\
\hline \multirow[t]{4}{*}{ C $1 \mathrm{~s}$} & C-B & 283.06 & 6 \\
\hline & $\mathrm{C}-\mathrm{C}$ & 284.81 & 11 \\
\hline & $\mathrm{C}-\mathrm{O}$ & 286.80 & 3 \\
\hline & $C=O$ & 289.04 & 1 \\
\hline $\mathrm{Na} 1 \mathrm{~s}$ & sodium salt & 1071.57 & 11 \\
\hline
\end{tabular}



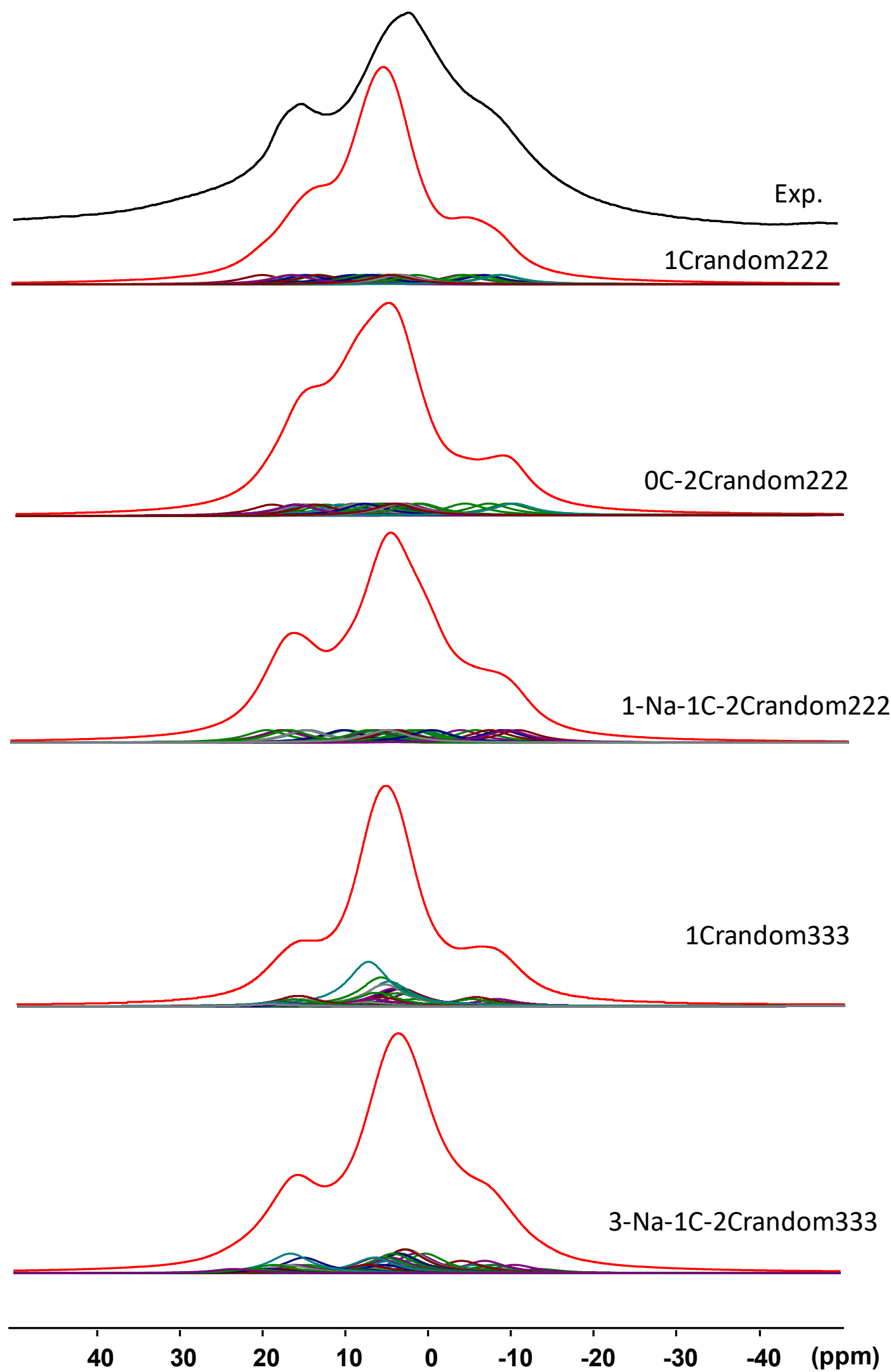

Figure S5. ${ }^{11} \mathrm{~B}$ experimental solid-state NMR spectrum of $\mathrm{NaB}_{5} \mathrm{C}$-related sodium carbaboride powder and calculated spectra of the different models proposed replacing quadrupolar lineshapes by broadened Gaussian lines. 

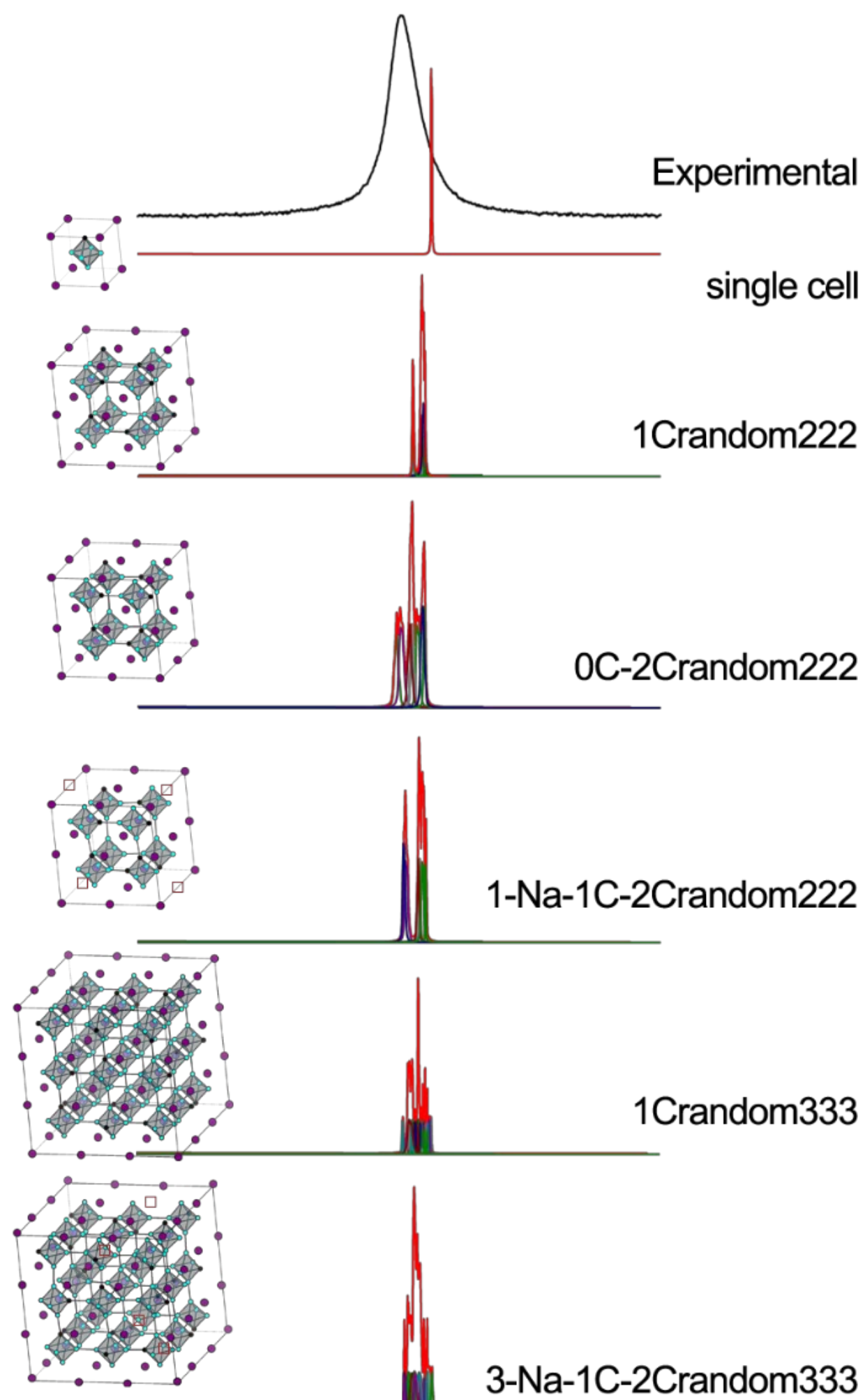

3-Na-1C-2Crandom333

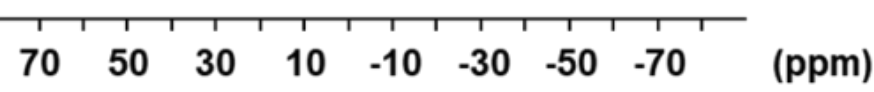

Figure S6. ${ }^{23} \mathrm{Na}$ experimental solid-state $\mathrm{NMR}$ spectrum of $\mathrm{NaB}_{5} \mathrm{C}$-related sodium carbaboride powder and calculated spectra for the different structural models, detailed in Figure 5 of the main text. The single cell spectrum is calculated from the reported structure of $\mathrm{NaB}_{5} \mathrm{C}$, where the carbon atom in $\mathrm{B}_{5} \mathrm{C}$ octahedra is always at the same position (equivalent of a $2 \times 2 \times 2$ or a $3 \times 3 \times 3$ supercell with iso-located carbon atoms in each octahedral cluster). 
Table S4. Crystallographic data of the $\mathbf{1 C r a n d o m} 222$ model (occupancy is 1 for all atoms).

$\begin{array}{cc}\text { Space group } & P 1 \\ \boldsymbol{a}, \boldsymbol{b}, \boldsymbol{c}(\boldsymbol{A}) & 8.1848 \\ \boldsymbol{\alpha}, \boldsymbol{\beta}, \boldsymbol{\gamma}\left(\mathbf{(}^{\circ}\right) & 90\end{array}$

\begin{tabular}{|c|c|c|c|}
\hline Atom & $x$ & $y$ & $z$ \\
\hline B1 & 0.41567923 & 0.74877276 & 0.25844785 \\
\hline B2 & 0.11362724 & 0.24805481 & 0.74825343 \\
\hline B3 & 0.26368005 & 0.25134904 & 0.89674660 \\
\hline B4 & 0.41658274 & 0.24992639 & 0.74843991 \\
\hline B5 & 0.25942187 & 0.40062633 & 0.74459778 \\
\hline B6 & 0.26092943 & 0.74950168 & 0.10896587 \\
\hline B7 & 0.11281897 & 0.74806665 & 0.25814057 \\
\hline B8 & 0.25828437 & 0.75327947 & 0.41201448 \\
\hline B9 & 0.74648637 & 0.89648115 & 0.74818651 \\
\hline B10 & 0.26151212 & 0.90080020 & 0.25746276 \\
\hline B11 & 0.73557069 & 0.39698255 & 0.24864831 \\
\hline B12 & 0.08813966 & 0.75690838 & 0.75084005 \\
\hline B13 & 0.24281487 & 0.60655958 & 0.74826239 \\
\hline B14 & 0.24464921 & 0.75307547 & 0.90213276 \\
\hline B15 & 0.39131434 & 0.75606960 & 0.74935149 \\
\hline B16 & 0.24528155 & 0.90977610 & 0.75137830 \\
\hline B17 & 0.73559335 & 0.24754956 & 0.09922501 \\
\hline B18 & 0.58056283 & 0.25031425 & 0.24876948 \\
\hline B19 & 0.26343755 & 0.24886892 & 0.59894115 \\
\hline B20 & 0.73530937 & 0.09820252 & 0.24864056 \\
\hline B21 & 0.75411426 & 0.24693577 & 0.59973514 \\
\hline B22 & 0.74637364 & 0.74752175 & 0.89673752 \\
\hline B23 & 0.74734867 & 0.59859051 & 0.74825689 \\
\hline B24 & 0.59668760 & 0.74905982 & 0.74534722 \\
\hline B25 & 0.74752725 & 0.74755350 & 0.59894985 \\
\hline B26 & 0.75341263 & 0.89525446 & 0.24881542 \\
\hline B27 & 0.90639577 & 0.74412637 & 0.25043144 \\
\hline B28 & 0.75678234 & 0.74685857 & 0.39790926 \\
\hline B29 & 0.75317487 & 0.59773290 & 0.24887044 \\
\hline B30 & 0.24266133 & 0.40997587 & 0.25233277 \\
\hline B31 & 0.75601922 & 0.74693980 & 0.09972925 \\
\hline B32 & 0.75725919 & 0.39547566 & 0.74863162 \\
\hline B33 & 0.90710186 & 0.24407293 & 0.74869764 \\
\hline B34 & 0.75398194 & 0.24695003 & 0.89757775 \\
\hline B35 & 0.75610093 & 0.09749135 & 0.74865222 \\
\hline B36 & 0.24265321 & 0.25541433 & 0.09919182 \\
\hline B37 & 0.08287637 & 0.25613927 & 0.24878567 \\
\hline B38 & 0.24169427 & 0.10608591 & 0.24935907 \\
\hline B39 & 0.24216631 & 0.25328213 & 0.39839974 \\
\hline B40 & 0.73584644 & 0.24751038 & 0.39792823 \\
\hline $\mathrm{C} 1$ & 0.61412814 & 0.74476389 & 0.25144510 \\
\hline
\end{tabular}




$\begin{array}{llll}\text { C2 } & & \\ \text { C3 } & 0.26184056 & 0.60725046 & 0.25973228 \\ \text { C4 } & 0.37999548 & 0.25661684 & 0.24914952 \\ \text { C5 } & 0.87688308 & 0.24954851 & 0.24866533 \\ \text { C6 } & 0.88869223 & 0.75000417 & 0.74626745 \\ \text { C7 } & 0.24373003 & 0.75554713 & 0.60863191 \\ \text { C8 } & 0.61487804 & 0.24511733 & 0.74850685 \\ \mathrm{Na} 1 & 0.26041506 & 0.10739938 & 0.74662314 \\ \mathrm{Na} 2 & 0.50656418 & 0.99108187 & 0.99842819 \\ \mathrm{Na} 3 & 0.50694671 & 0.50350787 & 0.98721665 \\ \mathrm{Na4} & 0.51311516 & 0.99687065 & 0.50005098 \\ \mathrm{Na} 5 & 0.99485082 & 0.49786866 & 0.99262505 \\ \mathrm{Na} 6 & 0.98944568 & 0.49208753 & 0.50412743 \\ \mathrm{Na} 7 & 0.99424268 & 0.99814700 & 0.00469745 \\ \mathrm{Na} 8 & 0.98910387 & 0.00293471 & 0.49235125 \\ & 0.51329439 & 0.49711729 & 0.50969718\end{array}$

Table S5. Crystallographic data of the 0C-2Crandom222 model (occupancy is 1 for all atoms).

$\begin{array}{cc}\text { Space group } & P 1 \\ \boldsymbol{a}, \boldsymbol{b}, \boldsymbol{c}(\boldsymbol{A}) & 8.1848 \\ \boldsymbol{\alpha}, \boldsymbol{\beta}, \boldsymbol{Y}\left(\left(^{\circ}\right)\right. & 90\end{array}$

\begin{tabular}{llll}
\hline Atom & $\boldsymbol{x}$ & $\boldsymbol{y}$ & $\boldsymbol{z}$ \\
\hline B1 & 0.41187720 & 0.74492394 & 0.25804653 \\
B2 & 0.11242339 & 0.24650157 & 0.74852633 \\
B3 & 0.26266035 & 0.25023722 & 0.89710000 \\
B4 & 0.41525855 & 0.24882842 & 0.74857669 \\
B5 & 0.26022834 & 0.39933435 & 0.74519320 \\
B6 & 0.25926697 & 0.74849759 & 0.10835420 \\
B7 & 0.11072882 & 0.74405678 & 0.25902902 \\
B8 & 0.25876262 & 0.75216839 & 0.41302401 \\
B9 & 0.74604843 & 0.89469193 & 0.74786253 \\
B10 & 0.25963411 & 0.89961364 & 0.25781434 \\
B11 & 0.73455604 & 0.40866331 & 0.24877533 \\
B12 & 0.10125467 & 0.75649936 & 0.74866425 \\
B13 & 0.25153598 & 0.60592194 & 0.74900965 \\
B14 & 0.25225846 & 0.75221465 & 0.90136226 \\
B15 & 0.39933484 & 0.75500569 & 0.74922154 \\
B16 & 0.25348875 & 0.90815132 & 0.75201016 \\
B17 & 0.73563074 & 0.25524922 & 0.09892092 \\
B18 & 0.57954631 & 0.25819730 & 0.24902432 \\
B19 & 0.26244276 & 0.24805321 & 0.59921549 \\
B20 & 0.73498614 & 0.10575432 & 0.24871536 \\
B21 & 0.75298097 & 0.24704045 & 0.60028063 \\
B22 & 0.89791262 & 0.74826861 & 0.74502538 \\
B23 & 0.74651755 & 0.74307858 & 0.89656238 \\
& & &
\end{tabular}




$\begin{array}{llll}\text { B24 } & & & \\ \mathrm{B} 25 & 0.74700323 & 0.59538708 & 0.74790785 \\ \mathrm{~B} 26 & 0.59875509 & 0.74644401 & 0.74539334 \\ \mathrm{~B} 27 & 0.74640408 & 0.74316242 & 0.59851728 \\ \mathrm{~B} 28 & 0.75240000 & 0.89630730 & 0.24863227 \\ \mathrm{~B} 29 & 0.90173876 & 0.74440662 & 0.25084393 \\ \mathrm{~B} 30 & 0.74880229 & 0.74451871 & 0.39832105 \\ \mathrm{~B} 31 & 0.24195276 & 0.40917174 & 0.25252012 \\ \mathrm{~B} 32 & 0.74888364 & 0.74420197 & 0.09882141 \\ \mathrm{~B} 33 & 0.75263061 & 0.39405750 & 0.74868089 \\ \mathrm{~B} 34 & 0.90445158 & 0.24272258 & 0.74887980 \\ \mathrm{~B} 35 & 0.75274660 & 0.24703247 & 0.89728221 \\ \mathrm{~B} 36 & 0.75088949 & 0.09593671 & 0.74866500 \\ \mathrm{~B} 37 & 0.24236494 & 0.25446895 & 0.09943979 \\ \mathrm{~B} 38 & 0.08270611 & 0.25899943 & 0.24901975 \\ \mathrm{~B} 39 & 0.24064954 & 0.10577733 & 0.24979710 \\ \mathrm{~B} 40 & 0.24183531 & 0.25258676 & 0.39880808 \\ \mathrm{C} 1 & 0.73592937 & 0.25515924 & 0.39861099 \\ \mathrm{C} 2 & 0.61109246 & 0.74501095 & 0.25057126 \\ \mathrm{C} 3 & 0.26054441 & 0.60535718 & 0.25969931 \\ \mathrm{C} 4 & 0.37937360 & 0.25798695 & 0.24939557 \\ \mathrm{C} 5 & 0.87708578 & 0.25889397 & 0.24886064 \\ \mathrm{C} 6 & 0.75105060 & 0.60569771 & 0.24884313 \\ \mathrm{C} 7 & 0.25265881 & 0.75424267 & 0.60934413 \\ \mathrm{C} 8 & 0.61261275 & 0.24435873 & 0.74862069 \\ \mathrm{Na} 1 & 0.26161749 & 0.10633508 & 0.74695543 \\ \mathrm{Na} 2 & 0.50638675 & 0.99007868 & 0.98670774 \\ \mathrm{Na3} & 0.50188830 & 0.50434089 & 0.97105559 \\ \mathrm{~N} a 4 & 0.51212583 & 0.99581465 & 0.51104737 \\ \mathrm{Na5} & 0.00077493 & 0.50111186 & 0.96905867 \\ \mathrm{Na} 9 & 0.99553712 & 0.49582163 & 0.52725643 \\ \mathrm{Na8} & 0.99249361 & 0.99083717 & 0.98519891 \\ & 0.98755228 & 0.99500459 & 0.51145093 \\ & 0.50772722 & 0.49781465 & 0.52547884\end{array}$

Table S6. Crystallographic data of the $\mathbf{1 C r a n d o m} 333$ model (occupancy is 1 for all atoms).

$\begin{array}{cc}\text { Space group } & P 1 \\ \boldsymbol{a}, \boldsymbol{b}, \boldsymbol{c}(\boldsymbol{A}) & 12.2772 \\ \boldsymbol{\alpha}, \boldsymbol{\beta}, \boldsymbol{Y}\left(\mathbf{(}^{\circ}\right) & 90\end{array}$

\begin{tabular}{llll}
\hline Atom & $\boldsymbol{x}$ & $\boldsymbol{y}$ & $\boldsymbol{z}$ \\
\hline B1 & 0.16437790 & 0.93206549 & 0.49240358 \\
B2 & 0.40731945 & 0.83503852 & 0.16399885 \\
B3 & 0.16001447 & 0.17206294 & 0.93624598 \\
B4 & 0.94283528 & 0.15678575 & 0.83202604 \\
B5 & 0.16338624 & 0.50157663 & 0.40889285 \\
B6 & 0.16000271 & 0.26841789 & 0.82973985
\end{tabular}




\begin{tabular}{|c|c|c|c|}
\hline B7 & 0.60354277 & 0.17997699 & 0.16064547 \\
\hline B8 & 0.50095545 & 0.16242808 & 0.40109484 \\
\hline B9 & 0.59872164 & 0.50527322 & 0.49514391 \\
\hline B10 & 0.50265886 & 0.50222367 & 0.59745662 \\
\hline B11 & 0.50182816 & 0.40134710 & 0.49689944 \\
\hline B12 & 0.40013459 & 0.50055993 & 0.50235508 \\
\hline B13 & 0.50587253 & 0.73501794 & 0.16800923 \\
\hline B14 & 0.49492609 & 0.59873739 & 0.16550360 \\
\hline B15 & 0.59055934 & 0.49239894 & 0.16474640 \\
\hline B16 & 0.49658809 & 0.27431290 & 0.16865258 \\
\hline B17 & 0.49071770 & 0.49951291 & 0.26805094 \\
\hline B18 & 0.38641330 & 0.50171091 & 0.16692981 \\
\hline B19 & 0.48858997 & 0.49818555 & 0.06467602 \\
\hline B20 & 0.50270706 & 0.26388639 & 0.49831689 \\
\hline B21 & 0.59841731 & 0.15671908 & 0.50236411 \\
\hline B22 & 0.49893648 & 0.16921487 & 0.60326327 \\
\hline B23 & 0.50439075 & 0.84164617 & 0.26471606 \\
\hline B24 & 0.39996031 & 0.16423528 & 0.49963799 \\
\hline B25 & 0.15860080 & 0.50634492 & 0.26984244 \\
\hline B26 & 0.26432864 & 0.17372730 & 0.83852013 \\
\hline B27 & 0.05727321 & 0.50685512 & 0.82121445 \\
\hline B28 & 0.50086649 & 0.50044939 & 0.73542973 \\
\hline B29 & 0.39648125 & 0.50032019 & 0.83122557 \\
\hline B30 & 0.49749303 & 0.39764547 & 0.83582890 \\
\hline B31 & 0.60854917 & 0.83339138 & 0.16857230 \\
\hline B32 & 0.59799181 & 0.49713411 & 0.83902076 \\
\hline B33 & 0.50022488 & 0.59980341 & 0.83879881 \\
\hline B34 & 0.49555603 & 0.82951274 & 0.74120890 \\
\hline B35 & 0.39987769 & 0.82432860 & 0.84258850 \\
\hline B36 & 0.50312208 & 0.82813826 & 0.94171972 \\
\hline B37 & 0.59874287 & 0.83180634 & 0.83621324 \\
\hline B38 & 0.49648930 & 0.92976004 & 0.84372464 \\
\hline B39 & 0.16697620 & 0.26415834 & 0.50451081 \\
\hline B40 & 0.50824198 & 0.93585474 & 0.15572840 \\
\hline B41 & 0.84058052 & 0.15260719 & 0.73311295 \\
\hline B42 & 0.74219632 & 0.16356921 & 0.83716135 \\
\hline B43 & 0.83848669 & 0.05757870 & 0.83779893 \\
\hline B44 & 0.60315138 & 0.16807002 & 0.84342955 \\
\hline B45 & 0.15662251 & 0.50676764 & 0.06524653 \\
\hline B46 & 0.49871859 & 0.06908914 & 0.84495512 \\
\hline B47 & 0.15506988 & 0.40596026 & 0.82519891 \\
\hline B48 & 0.15665134 & 0.50790928 & 0.92536735 \\
\hline B49 & 0.25848883 & 0.50486904 & 0.82810631 \\
\hline B50 & 0.50032414 & 0.84467873 & 0.40160506 \\
\hline B51 & 0.15796029 & 0.60786551 & 0.82368584 \\
\hline B52 & 0.15767720 & 0.40653968 & 0.16837630 \\
\hline B53 & 0.16397595 & 0.83744476 & 0.73399954 \\
\hline B54 & 0.06646991 & 0.83582611 & 0.83501210 \\
\hline
\end{tabular}




\begin{tabular}{|c|c|c|c|}
\hline B55 & 0.50099307 & 0.17426912 & 0.94184269 \\
\hline B56 & 0.16568065 & 0.82352896 & 0.93195402 \\
\hline B57 & 0.26465923 & 0.82594453 & 0.83369604 \\
\hline B58 & 0.16904604 & 0.93094817 & 0.83974728 \\
\hline B59 & 0.05740879 & 0.50646883 & 0.16780993 \\
\hline B60 & 0.50210363 & 0.16809023 & 0.74222252 \\
\hline B61 & 0.40111593 & 0.17211215 & 0.84188380 \\
\hline B62 & 0.83863441 & 0.60298560 & 0.50193259 \\
\hline B63 & 0.49849564 & 0.74050289 & 0.49591915 \\
\hline B64 & 0.49679778 & 0.83368626 & 0.60293830 \\
\hline B65 & 0.06593218 & 0.16637160 & 0.49643630 \\
\hline B66 & 0.16672279 & 0.82538720 & 0.39946754 \\
\hline B67 & 0.60056438 & 0.84196034 & 0.50342461 \\
\hline B68 & 0.16426935 & 0.92964615 & 0.16544592 \\
\hline B69 & 0.16788128 & 0.82770474 & 0.26441516 \\
\hline B70 & 0.82733474 & 0.49729439 & 0.72451009 \\
\hline B71 & 0.73498280 & 0.49480220 & 0.83330137 \\
\hline B72 & 0.83935544 & 0.39616016 & 0.82470063 \\
\hline B73 & 0.84243097 & 0.49631526 & 0.92449760 \\
\hline B74 & 0.83273639 & 0.59735402 & 0.82501444 \\
\hline B75 & 0.16277353 & 0.16094757 & 0.59904007 \\
\hline B76 & 0.83863926 & 0.84151609 & 0.73493582 \\
\hline B77 & 0.73412901 & 0.83132144 & 0.82984837 \\
\hline B78 & 0.83490032 & 0.73364904 & 0.82812497 \\
\hline B79 & 0.82916669 & 0.82919134 & 0.93269905 \\
\hline B80 & 0.93263048 & 0.83247211 & 0.83747966 \\
\hline B81 & 0.16232418 & 0.06607835 & 0.49452185 \\
\hline B82 & 0.16797995 & 0.82519723 & 0.06659307 \\
\hline B83 & 0.06831863 & 0.82652678 & 0.16534352 \\
\hline B84 & 0.16461348 & 0.73352897 & 0.50669083 \\
\hline B85 & 0.26938964 & 0.83321303 & 0.16389399 \\
\hline B86 & 0.26427015 & 0.16193839 & 0.49974083 \\
\hline B87 & 0.49655205 & 0.94032491 & 0.50644153 \\
\hline B88 & 0.83038813 & 0.82847798 & 0.06709025 \\
\hline B89 & 0.73438852 & 0.15616149 & 0.49900659 \\
\hline B90 & 0.83647757 & 0.15908158 & 0.59653197 \\
\hline B91 & 0.93208801 & 0.16847063 & 0.49327350 \\
\hline B92 & 0.82804038 & 0.26414322 & 0.50265903 \\
\hline B93 & 0.16492016 & 0.83806920 & 0.59900730 \\
\hline B94 & 0.83909107 & 0.49272563 & 0.06271292 \\
\hline B95 & 0.73122087 & 0.48529177 & 0.16251376 \\
\hline B96 & 0.83823580 & 0.39080388 & 0.16247784 \\
\hline B97 & 0.83465357 & 0.49103221 & 0.26428743 \\
\hline B98 & 0.82556894 & 0.59069198 & 0.16445141 \\
\hline B99 & 0.16084261 & 0.17031528 & 0.07345240 \\
\hline B100 & 0.83963190 & 0.49954365 & 0.40146610 \\
\hline B101 & 0.73451884 & 0.50649565 & 0.49490772 \\
\hline B102 & 0.82916231 & 0.40132683 & 0.50274427 \\
\hline
\end{tabular}




\begin{tabular}{|c|c|c|c|}
\hline B103 & 0.26738831 & 0.83499701 & 0.49998521 \\
\hline B104 & 0.83148782 & 0.17047531 & 0.39576668 \\
\hline B105 & 0.16434110 & 0.26970589 & 0.17370046 \\
\hline B106 & 0.16442548 & 0.06800136 & 0.17139607 \\
\hline B107 & 0.94210874 & 0.16542832 & 0.16459995 \\
\hline B108 & 0.83048825 & 0.72782455 & 0.16643601 \\
\hline B109 & 0.83598271 & 0.83026341 & 0.26508371 \\
\hline B110 & 0.93266047 & 0.82399229 & 0.16423295 \\
\hline B111 & 0.83615879 & 0.92886607 & 0.16381946 \\
\hline B112 & 0.49662180 & 0.60259242 & 0.49466751 \\
\hline B113 & 0.26500245 & 0.16891032 & 0.16879926 \\
\hline B114 & 0.84024669 & 0.83657996 & 0.40037124 \\
\hline B115 & 0.74226750 & 0.84269374 & 0.50200692 \\
\hline B116 & 0.84282542 & 0.74141035 & 0.50561312 \\
\hline B117 & 0.84512968 & 0.84781873 & 0.59976181 \\
\hline B118 & 0.84379990 & 0.94240215 & 0.49491711 \\
\hline B119 & 0.16712001 & 0.16879929 & 0.27402655 \\
\hline B120 & 0.84618805 & 0.16488170 & 0.05753561 \\
\hline B121 & 0.74183309 & 0.17263019 & 0.15304542 \\
\hline B122 & 0.83811224 & 0.06622150 & 0.15944897 \\
\hline B123 & 0.83580754 & 0.16689155 & 0.25837467 \\
\hline B124 & 0.93202213 & 0.49801412 & 0.50916506 \\
\hline B125 & 0.84555851 & 0.25858004 & 0.82813919 \\
\hline B126 & 0.50668577 & 0.07478846 & 0.15561186 \\
\hline B127 & 0.40185189 & 0.16993649 & 0.16557194 \\
\hline B128 & 0.16286107 & 0.59911284 & 0.51020495 \\
\hline B129 & 0.26509295 & 0.50113903 & 0.50609138 \\
\hline B130 & 0.16700301 & 0.39963069 & 0.50693696 \\
\hline B131 & 0.50414798 & 0.16654674 & 0.26382835 \\
\hline B132 & 0.06630119 & 0.49770231 & 0.51310722 \\
\hline B133 & 0.16177254 & 0.60645164 & 0.16760147 \\
\hline B134 & 0.16501191 & 0.16319106 & 0.73604047 \\
\hline B135 & 0.17053057 & 0.06794437 & 0.84064607 \\
\hline $\mathrm{C} 1$ & 0.73944555 & 0.83071767 & 0.16760654 \\
\hline $\mathrm{C} 2$ & 0.49534385 & 0.07041172 & 0.50559746 \\
\hline C3 & 0.49556191 & 0.49909915 & 0.40182460 \\
\hline $\mathrm{C} 4$ & 0.40222441 & 0.83940826 & 0.50066736 \\
\hline C5 & 0.49998911 & 0.17999217 & 0.07068511 \\
\hline C6 & 0.48669588 & 0.40402253 & 0.16637548 \\
\hline $\mathrm{C} 7$ & 0.50170088 & 0.26533103 & 0.84002732 \\
\hline C8 & 0.49265798 & 0.49627040 & 0.93186903 \\
\hline C9 & 0.50194309 & 0.73305070 & 0.84275797 \\
\hline C10 & 0.07188784 & 0.16237553 & 0.83538976 \\
\hline C11 & 0.16309806 & 0.50399680 & 0.72947455 \\
\hline C12 & 0.92678733 & 0.49798028 & 0.16529635 \\
\hline C13 & 0.16146544 & 0.73796442 & 0.82613698 \\
\hline C14 & 0.07024254 & 0.83461804 & 0.49801801 \\
\hline C15 & 0.16700807 & 0.49943753 & 0.60343474 \\
\hline
\end{tabular}




\begin{tabular}{|c|c|c|c|}
\hline C16 & 0.16527509 & 0.16890983 & 0.40507069 \\
\hline $\mathrm{C} 17$ & 0.17039775 & 0.73587058 & 0.16646839 \\
\hline C18 & 0.50873946 & 0.82945228 & 0.07125525 \\
\hline C19 & 0.25270743 & 0.50333136 & 0.16687968 \\
\hline $\mathrm{C} 20$ & 0.07137218 & 0.16935090 & 0.17411182 \\
\hline $\mathrm{C} 21$ & 0.84649101 & 0.26090036 & 0.15857964 \\
\hline $\mathrm{C} 22$ & 0.83997962 & 0.07161803 & 0.49202394 \\
\hline $\mathrm{C} 23$ & 0.82853689 & 0.50123852 & 0.59468419 \\
\hline C24 & 0.94055275 & 0.83949412 & 0.49794876 \\
\hline $\mathrm{C} 25$ & 0.83431836 & 0.92693764 & 0.84028479 \\
\hline C26 & 0.92788596 & 0.50085482 & 0.81812736 \\
\hline $\mathrm{C} 27$ & 0.84640159 & 0.16331011 & 0.92744180 \\
\hline $\mathrm{Na} 1$ & 0.99934649 & 0.99626197 & 0.32201229 \\
\hline $\mathrm{Na} 2$ & 0.66731631 & 0.00061080 & 0.99831650 \\
\hline $\mathrm{Na} 3$ & 0.67036457 & 0.66841121 & 0.33793488 \\
\hline $\mathrm{Na} 4$ & 0.67920933 & 0.65846729 & 0.99763717 \\
\hline $\mathrm{Na} 5$ & 0.33435045 & 0.67127600 & 0.33779580 \\
\hline $\mathrm{Na} 6$ & 0.32810964 & 0.66829037 & 0.00003070 \\
\hline $\mathrm{Na} 7$ & 0.99526530 & 0.66255681 & 0.33698996 \\
\hline $\mathrm{Na} 8$ & 0.99137228 & 0.67303210 & 0.99821452 \\
\hline $\mathrm{Na9}$ & 0.66634100 & 0.67239806 & 0.66142683 \\
\hline Na10 & 0.66565555 & 0.32694159 & 0.66166442 \\
\hline $\mathrm{Na} 11$ & 0.66145293 & 0.99941242 & 0.67328484 \\
\hline $\mathrm{Na} 12$ & 0.00763083 & 0.33998876 & 0.99428406 \\
\hline $\mathrm{Na} 13$ & 0.34267724 & 0.66848338 & 0.66166733 \\
\hline $\mathrm{Na} 14$ & 0.33760588 & 0.32455572 & 0.66072618 \\
\hline Na15 & 0.32863425 & 0.00317296 & 0.67813021 \\
\hline $\mathrm{Na} 16$ & 0.99250306 & 0.67858152 & 0.66632388 \\
\hline $\mathrm{Na} 17$ & 0.99596761 & 0.31746153 & 0.65760209 \\
\hline Na18 & 0.00953286 & 0.00164930 & 0.66957722 \\
\hline $\mathrm{Na} 19$ & 0.66970008 & 0.32737088 & 0.34145813 \\
\hline $\mathrm{Na} 20$ & 0.33142146 & 0.32532662 & 0.34388148 \\
\hline $\mathrm{Na} 21$ & 0.31313716 & 0.33141592 & 0.99692526 \\
\hline $\mathrm{Na} 22$ & 0.99951464 & 0.33885049 & 0.34935508 \\
\hline $\mathrm{Na} 23$ & 0.32595532 & 0.99983047 & 0.00008149 \\
\hline $\mathrm{Na} 24$ & 0.00687643 & 0.98432007 & 0.00604735 \\
\hline $\mathrm{Na} 25$ & 0.33433961 & 0.99925506 & 0.32154274 \\
\hline $\mathrm{Na} 26$ & 0.67900162 & 0.33534753 & 0.99318032 \\
\hline $\mathrm{Na} 27$ & 0.66606554 & 0.00495338 & 0.32726952 \\
\hline
\end{tabular}


Table S7. Crystallographic data of the 1-Na-1C-2Crandom222 model (occupancy is 1 for all atoms).

$\begin{array}{cc}\text { Space group } & P 1 \\ \boldsymbol{a}, \boldsymbol{b}, \boldsymbol{c}(\boldsymbol{A}) & 8.1848 \\ \boldsymbol{\alpha}, \boldsymbol{\beta}, \boldsymbol{\gamma}\left(^{\circ}\right) & 90\end{array}$

\begin{tabular}{llll}
\hline Atom & $\boldsymbol{x}$ & $\boldsymbol{y}$ & $\boldsymbol{z}$ \\
\hline B1 & 0.41178098 & 0.74584135 & 0.25821610 \\
B2 & 0.11250925 & 0.24616120 & 0.74766357 \\
B3 & 0.26269827 & 0.25224894 & 0.89677322 \\
B4 & 0.41512868 & 0.24627215 & 0.74865854 \\
B5 & 0.26179394 & 0.40086788 & 0.74473655 \\
B6 & 0.25965865 & 0.74984185 & 0.10823417 \\
B7 & 0.11089391 & 0.74616109 & 0.25939959 \\
B8 & 0.25757343 & 0.75532429 & 0.41282312 \\
B9 & 0.25925759 & 0.90105299 & 0.25769866 \\
B10 & 0.73459851 & 0.41035805 & 0.24812460 \\
B11 & 0.10159438 & 0.76003227 & 0.74809016 \\
B12 & 0.25362899 & 0.60865870 & 0.74825900 \\
B13 & 0.25260653 & 0.75482942 & 0.90108866 \\
B14 & 0.39942741 & 0.76087529 & 0.74915950 \\
B15 & 0.25209649 & 0.91135764 & 0.75004045 \\
B16 & 0.73521636 & 0.25525409 & 0.09863692 \\
B17 & 0.57942636 & 0.25986118 & 0.24856329 \\
B18 & 0.26226978 & 0.24920642 & 0.59856044 \\
B19 & 0.73492153 & 0.10761888 & 0.24918060 \\
B20 & 0.75283284 & 0.23743707 & 0.59958593 \\
B21 & 0.89800844 & 0.74889624 & 0.74532011 \\
B22 & 0.74634150 & 0.74300648 & 0.89615955 \\
B23 & 0.74646234 & 0.59298696 & 0.74818842 \\
B24 & 0.59965055 & 0.74910554 & 0.74566100 \\
B25 & 0.74723134 & 0.74280286 & 0.59890512 \\
B26 & 0.75263193 & 0.89969075 & 0.24961435 \\
B27 & 0.90231448 & 0.74726706 & 0.25170954 \\
B28 & 0.75001666 & 0.75000487 & 0.39783285 \\
B29 & 0.24157082 & 0.41034495 & 0.25184159 \\
B30 & 0.74899545 & 0.74959753 & 0.09961520 \\
B31 & 0.75203865 & 0.38547794 & 0.74876255 \\
B32 & 0.90534628 & 0.23470431 & 0.74786554 \\
B33 & 0.75189712 & 0.23739598 & 0.89733677 \\
B34 & 0.75527719 & 0.08254988 & 0.74654119 \\
B35 & 0.24209065 & 0.25606579 & 0.09925194 \\
B36 & 0.08246085 & 0.25867970 & 0.25019613 \\
B37 & 0.10702976 & 0.25006907 \\
B38 & 0.25336737 & 0.39839760 \\
C1 & 0.25526886 & 0.39867941 \\
\hline & 0.88580020 & 0.74673386 \\
\hline
\end{tabular}




$\begin{array}{llll}\text { C2 } & 0.61087986 & 0.74640195 & 0.25059599 \\ \text { C3 } & 0.26060705 & 0.60656171 & 0.25902262 \\ \text { C4 } & 0.37931835 & 0.25982001 & 0.24875351 \\ \text { C5 } & 0.87668155 & 0.25939105 & 0.24937921 \\ \text { C6 } & 0.75082303 & 0.60844655 & 0.24818837 \\ \text { C7 } & 0.25195165 & 0.75763502 & 0.60882206 \\ \text { C8 } & 0.61219412 & 0.23408030 & 0.74882916 \\ \text { C9 } & 0.26064060 & 0.10825117 & 0.74603597 \\ \mathrm{Na} 1 & 0.49361886 & 0.99826489 & 0.00004762 \\ \mathrm{Na} 2 & 0.49611609 & 0.49959622 & 0.97759224 \\ \mathrm{Na3} & 0.50155359 & 0.00422092 & 0.49805845 \\ \mathrm{Na} 4 & 0.00813391 & 0.49472529 & 0.97451200 \\ \mathrm{Na} 5 & 0.00218938 & 0.48750429 & 0.52088059 \\ \mathrm{Na} 6 & 0.00683051 & 0.99814724 & 0.99659052 \\ \mathrm{Na} 7 & 0.50215472 & 0.49264660 & 0.51906378\end{array}$

Table S8. Crystallographic data of the 3-Na-1C-2Crandom333 model (occupancy is 1 for all atoms).

$\begin{array}{cc}\text { Space group } & P 1 \\ \boldsymbol{a}, \boldsymbol{b}, \boldsymbol{c}(\boldsymbol{A}) & 12.2772 \\ \boldsymbol{\alpha}, \boldsymbol{\beta}, \boldsymbol{V}\left(\mathbf{(}^{\circ}\right) & 90\end{array}$

\begin{tabular}{llll}
\hline Atom & $\boldsymbol{x}$ & $\boldsymbol{y}$ & $\boldsymbol{z}$ \\
\hline B1 & 0.16524991 & 0.93156059 & 0.49505602 \\
B2 & 0.40757383 & 0.83562452 & 0.16256814 \\
B3 & 0.15981314 & 0.17085158 & 0.93693295 \\
B4 & 0.94188951 & 0.15698573 & 0.83343528 \\
B5 & 0.16564610 & 0.49384992 & 0.40895530 \\
B6 & 0.15949327 & 0.26863256 & 0.83169576 \\
B7 & 0.60353065 & 0.18025049 & 0.16200234 \\
B8 & 0.50033317 & 0.16044296 & 0.40258591 \\
B9 & 0.59874965 & 0.50770937 & 0.49291071 \\
B10 & 0.50399606 & 0.50101075 & 0.59806812 \\
B11 & 0.50334607 & 0.40195296 & 0.49750796 \\
B12 & 0.40088588 & 0.49804748 & 0.50423444 \\
B13 & 0.50646023 & 0.73551224 & 0.16634911 \\
B14 & 0.49558927 & 0.59955132 & 0.16527577 \\
B15 & 0.59065981 & 0.49333014 & 0.16749953 \\
B16 & 0.49692734 & 0.27452002 & 0.16983251 \\
B17 & 0.49134433 & 0.50239560 & 0.26928012 \\
B18 & 0.38722733 & 0.50177653 & 0.16684448 \\
B19 & 0.49015459 & 0.49871612 & 0.06493379 \\
B20 & 0.50356325 & 0.26403882 & 0.49883780 \\
B21 & 0.59830113 & 0.15529174 & 0.50390477 \\
B22 & 0.49815657 & 0.17086778 & 0.60498787
\end{tabular}




\begin{tabular}{|c|c|c|c|}
\hline B23 & 0.50510260 & 0.84101280 & 0.26395572 \\
\hline B24 & 0.40009158 & 0.16803851 & 0.50160680 \\
\hline B25 & 0.15970139 & 0.50438427 & 0.27068677 \\
\hline B26 & 0.26390028 & 0.17443105 & 0.83897388 \\
\hline B27 & 0.05704489 & 0.50692548 & 0.82122800 \\
\hline B28 & 0.50070021 & 0.49882070 & 0.73543135 \\
\hline B29 & 0.39655943 & 0.50004250 & 0.83141434 \\
\hline B30 & 0.49628244 & 0.39780830 & 0.83570184 \\
\hline B31 & 0.60884861 & 0.83301436 & 0.16815358 \\
\hline B32 & 0.59763800 & 0.49724251 & 0.83875467 \\
\hline B33 & 0.50024500 & 0.60002560 & 0.83653813 \\
\hline B34 & 0.49735111 & 0.83332093 & 0.73252725 \\
\hline B35 & 0.40019430 & 0.82428582 & 0.83425610 \\
\hline B36 & 0.50266496 & 0.82936458 & 0.93510354 \\
\hline B37 & 0.59909987 & 0.83254454 & 0.82886372 \\
\hline B38 & 0.49692462 & 0.93126181 & 0.83734668 \\
\hline B39 & 0.50880223 & 0.93615500 & 0.15422522 \\
\hline B40 & 0.83973048 & 0.15357999 & 0.73417399 \\
\hline B41 & 0.74124720 & 0.16357098 & 0.83730860 \\
\hline B42 & 0.83678833 & 0.05787320 & 0.83790629 \\
\hline B43 & 0.60236433 & 0.16813260 & 0.84355916 \\
\hline B44 & 0.15470732 & 0.50777955 & 0.06584624 \\
\hline B45 & 0.49853729 & 0.07028516 & 0.84335970 \\
\hline B46 & 0.15471986 & 0.40550495 & 0.82712103 \\
\hline B47 & 0.15544760 & 0.50845039 & 0.92581782 \\
\hline B48 & 0.25829327 & 0.50422156 & 0.82879128 \\
\hline B49 & 0.50265226 & 0.84409173 & 0.40339949 \\
\hline B50 & 0.15753529 & 0.60732510 & 0.82339022 \\
\hline B51 & 0.15758748 & 0.40670141 & 0.16743860 \\
\hline B52 & 0.16199830 & 0.83637381 & 0.73453182 \\
\hline B53 & 0.06635913 & 0.83550513 & 0.83702435 \\
\hline B54 & 0.50070887 & 0.17439534 & 0.94227743 \\
\hline B55 & 0.16757163 & 0.82383087 & 0.93221782 \\
\hline B56 & 0.26468646 & 0.82587901 & 0.83143434 \\
\hline B57 & 0.16884772 & 0.93089122 & 0.83886168 \\
\hline B58 & 0.05753463 & 0.50681866 & 0.17111426 \\
\hline B59 & 0.50162656 & 0.17054636 & 0.74299745 \\
\hline B60 & 0.40047845 & 0.17352561 & 0.84266716 \\
\hline B61 & 0.83990829 & 0.60335507 & 0.49501647 \\
\hline B62 & 0.49741069 & 0.74125887 & 0.49971975 \\
\hline B63 & 0.06627685 & 0.16902133 & 0.49631321 \\
\hline B64 & 0.16905937 & 0.82486887 & 0.40085131 \\
\hline B65 & 0.60094145 & 0.84232337 & 0.50463553 \\
\hline B66 & 0.16448750 & 0.93012724 & 0.16706111 \\
\hline B67 & 0.16927915 & 0.82806106 & 0.26551802 \\
\hline B68 & 0.82745009 & 0.49683475 & 0.72120231 \\
\hline B69 & 0.73448053 & 0.49506413 & 0.83136521 \\
\hline B70 & 0.83887283 & 0.39635573 & 0.82425672 \\
\hline
\end{tabular}




\begin{tabular}{|c|c|c|c|}
\hline B71 & 0.84123747 & 0.49695644 & 0.92392552 \\
\hline B72 & 0.83297334 & 0.59746858 & 0.82337828 \\
\hline B73 & 0.16262965 & 0.16340329 & 0.60026243 \\
\hline B74 & 0.84050751 & 0.84165867 & 0.73549300 \\
\hline B75 & 0.73437645 & 0.83186131 & 0.82800541 \\
\hline B76 & 0.83499371 & 0.73374682 & 0.82774074 \\
\hline B77 & 0.82795242 & 0.82819593 & 0.93309465 \\
\hline B78 & 0.93249406 & 0.83242690 & 0.83983658 \\
\hline B79 & 0.16302905 & 0.06757093 & 0.49827652 \\
\hline B80 & 0.16839040 & 0.82589053 & 0.06735356 \\
\hline B81 & 0.06854967 & 0.82686746 & 0.16666859 \\
\hline B82 & 0.16560225 & 0.72984230 & 0.50674283 \\
\hline B83 & 0.26989442 & 0.83377939 & 0.16410936 \\
\hline B84 & 0.26473737 & 0.16600891 & 0.50073213 \\
\hline B85 & 0.49537173 & 0.94103686 & 0.50960752 \\
\hline B86 & 0.82994733 & 0.82684304 & 0.06776690 \\
\hline B87 & 0.73459307 & 0.15495619 & 0.50026168 \\
\hline B88 & 0.83660433 & 0.16047288 & 0.59785584 \\
\hline B89 & 0.93223886 & 0.17174381 & 0.49437922 \\
\hline B90 & 0.82652199 & 0.26449470 & 0.50141562 \\
\hline B91 & 0.16383553 & 0.83530683 & 0.60018343 \\
\hline B92 & 0.83746211 & 0.49357306 & 0.06454740 \\
\hline B93 & 0.73121885 & 0.48634200 & 0.16370612 \\
\hline B94 & 0.83866180 & 0.39148409 & 0.16531069 \\
\hline B95 & 0.82598984 & 0.59157267 & 0.16883721 \\
\hline B96 & 0.16109448 & 0.16980466 & 0.07466114 \\
\hline B97 & 0.83755503 & 0.49965033 & 0.39337299 \\
\hline B98 & 0.73386919 & 0.50900027 & 0.48814819 \\
\hline B99 & 0.82692961 & 0.40110186 & 0.49644109 \\
\hline B100 & 0.26803603 & 0.83382313 & 0.50392399 \\
\hline B101 & 0.83207399 & 0.16911897 & 0.39698300 \\
\hline B102 & 0.16449650 & 0.27043065 & 0.17395482 \\
\hline B103 & 0.16439586 & 0.06865978 & 0.17441877 \\
\hline B104 & 0.94213739 & 0.16616890 & 0.16568417 \\
\hline B105 & 0.82992728 & 0.72836962 & 0.17018708 \\
\hline B106 & 0.83449908 & 0.83185546 & 0.26625206 \\
\hline B107 & 0.93251661 & 0.82417150 & 0.16553623 \\
\hline B108 & 0.83612814 & 0.92891206 & 0.16289270 \\
\hline B109 & 0.49538517 & 0.60316732 & 0.49786688 \\
\hline B110 & 0.26541723 & 0.16970322 & 0.16946448 \\
\hline B111 & 0.83875450 & 0.83841142 & 0.40126313 \\
\hline B112 & 0.74282952 & 0.84298597 & 0.50512954 \\
\hline B113 & 0.84329630 & 0.74160301 & 0.50342680 \\
\hline B114 & 0.84664112 & 0.84703260 & 0.60072213 \\
\hline B115 & 0.84459230 & 0.94289095 & 0.49770370 \\
\hline B116 & 0.16775647 & 0.17159749 & 0.27510901 \\
\hline B117 & 0.84594016 & 0.16701270 & 0.05857039 \\
\hline B118 & 0.74172156 & 0.17331482 & 0.15451978 \\
\hline
\end{tabular}




\begin{tabular}{|c|c|c|c|}
\hline B119 & 0.83808249 & 0.06700713 & 0.15932009 \\
\hline B120 & 0.83610116 & 0.16619211 & 0.25996365 \\
\hline B121 & 0.93229327 & 0.49575860 & 0.50156277 \\
\hline B122 & 0.84482561 & 0.25890828 & 0.82932408 \\
\hline B123 & 0.50705124 & 0.07502093 & 0.15559917 \\
\hline B124 & 0.40223383 & 0.17042918 & 0.16616197 \\
\hline B125 & 0.16328186 & 0.59192413 & 0.50979420 \\
\hline B126 & 0.26616223 & 0.49318089 & 0.50826500 \\
\hline B127 & 0.16778968 & 0.39080893 & 0.50724554 \\
\hline B128 & 0.50393339 & 0.16547073 & 0.26492640 \\
\hline B129 & 0.06650133 & 0.49008772 & 0.51115238 \\
\hline B130 & 0.16220279 & 0.60682827 & 0.16922120 \\
\hline B131 & 0.16429257 & 0.16658890 & 0.73716767 \\
\hline B132 & 0.16958315 & 0.06814092 & 0.83966077 \\
\hline $\mathrm{C} 1$ & 0.16732816 & 0.25979067 & 0.50656141 \\
\hline $\mathrm{C} 2$ & 0.49933739 & 0.83600261 & 0.59905204 \\
\hline C3 & 0.83288468 & 0.49179992 & 0.26002906 \\
\hline $\mathrm{C} 4$ & 0.73931397 & 0.83051962 & 0.16851266 \\
\hline C5 & 0.49415225 & 0.07072544 & 0.50952126 \\
\hline $\mathrm{C} 6$ & 0.49559827 & 0.50237672 & 0.40268710 \\
\hline $\mathrm{C} 7$ & 0.40307191 & 0.84005602 & 0.50272379 \\
\hline C8 & 0.50022310 & 0.18033540 & 0.07144685 \\
\hline C9 & 0.48717195 & 0.40449016 & 0.16743839 \\
\hline C10 & 0.50019492 & 0.26613264 & 0.84107388 \\
\hline C11 & 0.49377275 & 0.49769703 & 0.93199580 \\
\hline C12 & 0.50192493 & 0.73343450 & 0.83622722 \\
\hline $\mathrm{C} 13$ & 0.07087430 & 0.16229073 & 0.83660276 \\
\hline C14 & 0.16300904 & 0.50028496 & 0.73011720 \\
\hline C15 & 0.92616995 & 0.49816178 & 0.16676065 \\
\hline C16 & 0.16128261 & 0.73759303 & 0.82634540 \\
\hline C17 & 0.07105214 & 0.83374678 & 0.49842892 \\
\hline C18 & 0.16676775 & 0.49210735 & 0.60405979 \\
\hline C19 & 0.16562697 & 0.16911747 & 0.40681292 \\
\hline $\mathrm{C} 20$ & 0.17093595 & 0.73633642 & 0.16764578 \\
\hline $\mathrm{C} 21$ & 0.50814061 & 0.83046761 & 0.06799603 \\
\hline $\mathrm{C} 22$ & 0.25249240 & 0.50332381 & 0.16677415 \\
\hline $\mathrm{C} 23$ & 0.07139971 & 0.17004383 & 0.17534046 \\
\hline $\mathrm{C} 24$ & 0.84628057 & 0.26195544 & 0.16245644 \\
\hline $\mathrm{C} 25$ & 0.84195714 & 0.07222922 & 0.49483381 \\
\hline $\mathrm{C} 26$ & 0.82925669 & 0.50064499 & 0.58785280 \\
\hline $\mathrm{C} 27$ & 0.94092486 & 0.83955334 & 0.49823502 \\
\hline $\mathrm{C} 28$ & 0.83361788 & 0.92687673 & 0.84031314 \\
\hline $\mathrm{C} 29$ & 0.92769257 & 0.50080106 & 0.81731492 \\
\hline C30 & 0.84593794 & 0.16478684 & 0.92857556 \\
\hline $\mathrm{Na} 1$ & 0.99441099 & 0.99251995 & 0.31943038 \\
\hline $\mathrm{Na} 2$ & 0.66523844 & 0.00004753 & 0.99085266 \\
\hline $\mathrm{Na} 3$ & 0.67458853 & 0.66394654 & 0.99465947 \\
\hline $\mathrm{Na} 4$ & 0.33787350 & 0.66819524 & 0.33607629 \\
\hline
\end{tabular}




$\begin{array}{llll}\mathrm{Na} 5 & 0.33075654 & 0.66876029 & 0.99775049 \\ \mathrm{Na} 6 & 0.99835693 & 0.67073124 & 0.34030072 \\ \mathrm{Na} 7 & 0.99402455 & 0.67751775 & 0.99540077 \\ \mathrm{Na} 8 & 0.67299165 & 0.66723174 & 0.66064755 \\ \mathrm{Na9} & 0.65948932 & 0.32216831 & 0.66353334 \\ \mathrm{Na} 10 & 0.00933601 & 0.33686646 & 0.98967517 \\ \mathrm{Na} 11 & 0.34038423 & 0.65549119 & 0.66584489 \\ \mathrm{Na} 12 & 0.33330989 & 0.01466156 & 0.68677006 \\ \mathrm{Na} 13 & 0.99122494 & 0.67852234 & 0.66700906 \\ \mathrm{Na} 14 & 0.98733028 & 0.32065550 & 0.66437272 \\ \mathrm{Na} 15 & 0.00319999 & 0.99917568 & 0.67621014 \\ \mathrm{Na} 16 & 0.66158987 & 0.32089523 & 0.34843780 \\ \mathrm{Na} 17 & 0.34251990 & 0.32866112 & 0.34317194 \\ \mathrm{Na} 18 & 0.31711590 & 0.33219416 & 0.99045383 \\ \mathrm{Na} 19 & 0.99812953 & 0.33525969 & 0.34740593 \\ \mathrm{Na} 20 & 0.32880722 & 0.00057589 & 0.99698042 \\ \mathrm{Na} 21 & 0.00522840 & 0.98367332 & 0.00468655 \\ \mathrm{Na} 22 & 0.33966988 & 0.00003701 & 0.31385679 \\ \mathrm{Na} 23 & 0.67318997 & 0.33169058 & 0.98802365 \\ \mathrm{Na} 24 & 0.66840004 & 0.00405148 & 0.32731438\end{array}$

Table S9. Calculated ${ }^{11} \mathrm{~B}$ and ${ }^{23} \mathrm{Na} \mathrm{NMR}$ parameters in the $\mathrm{NaB}_{5} \mathrm{C}$ structure (single cell) in which the $\mathrm{B} 3$ atom is in line with the $\mathrm{C}$ atom.

\begin{tabular}{|c|c|c|c|}
\hline & $\delta_{\text {iso }}(\mathrm{ppm})$ & $C_{Q}(\mathrm{MHz})$ & $\eta$ \\
\hline B1 & 5.4 & 1.74 & 0.56 \\
\hline B2 & 5.4 & 1.74 & 0.56 \\
\hline B3 & 12.3 & 0.44 & 0.00 \\
\hline B4 & 5.4 & 1.74 & 0.56 \\
\hline B5 & 5.4 & 1.74 & 0.56 \\
\hline Na & -15.2 & -0.62 & 0.0 \\
\hline
\end{tabular}

Table S10. Calculated ${ }^{11} \mathrm{~B}$ NMR parameters in the $\mathrm{Na}_{8}\left(\mathrm{~B}_{5} \mathrm{C}\right)_{8}$ model 1 Crandom 222.

\begin{tabular}{|c|c|c|c|c|c|c|c|}
\hline & $\delta_{\text {iso }}(\mathrm{ppm})$ & $C_{Q}(\mathrm{MHz})$ & $\eta$ & & $\delta_{\text {iso }}(\mathrm{ppm})$ & $C_{Q}(\mathrm{MHz})$ & $\eta$ \\
\hline B1 & 3.3 & -1.09 & 0.53 & B21 & 7.1 & -1.67 & 0.39 \\
\hline B2 & -4.3 & -1.55 & 0.21 & B22 & 5.0 & -1.73 & 0.59 \\
\hline
\end{tabular}




\begin{tabular}{|c|c|c|c|c|c|c|c|}
\hline B3 & 3.1 & -1.75 & 0.50 & B23 & 6.3 & -1.71 & 0.55 \\
\hline B4 & 5.7 & 1.08 & 0.95 & B24 & 13.1 & -1.52 & 0.01 \\
\hline B5 & 19.7 & -1.56 & 0.26 & B25 & 5.8 & -1.80 & 0.32 \\
\hline B6 & -6.1 & -1.59 & 0.38 & B26 & 3.7 & -1.63 & 0.59 \\
\hline B7 & -7.1 & -1.55 & 0.47 & B27 & 12.7 & -1.54 & 0.19 \\
\hline B8 & 7.3 & -1.18 & 0.59 & B28 & 8.7 & -1.80 & 0.29 \\
\hline B9 & 8.5 & -1.79 & 0.29 & B29 & 5.9 & -1.75 & 0.29 \\
\hline B10 & 14.7 & -1.61 & 0.17 & B30 & 2.8 & -0.95 & 0.61 \\
\hline B11 & 5.3 & -1.79 & 0.32 & B31 & 7.0 & -1.76 & 0.55 \\
\hline B12 & 4.5 & -1.07 & 0.67 & B32 & 4.5 & -1.72 & 0.60 \\
\hline B13 & -8.9 & -1.59 & 0.25 & B33 & 13.0 & -1.57 & 0.14 \\
\hline B14 & 14.3 & -1.62 & 0.02 & B34 & 7.6 & -1.71 & 0.38 \\
\hline B15 & -4.7 & -1.57 & 0.31 & B35 & 6.5 & -1.83 & 0.32 \\
\hline B16 & 4.4 & -1.09 & 0.83 & B36 & 1.1 & -1.73 & 0.20 \\
\hline B17 & 5.5 & -1.76 & 0.46 & B37 & 16.0 & -0.70 & 0.34 \\
\hline B18 & 16.4 & -0.81 & 0.02 & B38 & -9.2 & -1.52 & 0.55 \\
\hline B19 & 3.6 & -1.80 & 0.21 & B39 & 3.1 & -1.74 & 0.38 \\
\hline B20 & 3.8 & -1.70 & 0.62 & B40 & 4.2 & -1.71 & 0.46 \\
\hline
\end{tabular}

Table S11. Calculated ${ }^{11} \mathrm{~B}$ NMR parameters in the $\mathrm{Na}_{8}\left(\mathrm{~B}_{5} \mathrm{C}\right)_{6}\left(\mathrm{~B}_{4} \mathrm{C}_{2}\right)\left(\mathrm{B}_{6}\right)$ model $\mathbf{0 C}$ 2Crandom 222.

\begin{tabular}{|c|c|c|c|c|c|c|c|}
\hline & $\delta_{\text {iso }}(\mathrm{ppm})$ & $C_{Q}(\mathrm{MHz})$ & $\eta$ & & $\delta_{\text {iso }}(\mathrm{ppm})$ & $C_{Q}(\mathrm{MHz})$ & $\eta$ \\
\hline B1 & 1.0 & -0.72 & 0.78 & B21 & 5.8 & -1.61 & 0.47 \\
\hline B2 & -4.8 & -1.51 & 0.33 & B22 & 4.0 & -1.40 & 0.04 \\
\hline B3 & 3.4 & -1.76 & 0.48 & B23 & 3.1 & -1.17 & 0.25 \\
\hline B4 & 6.8 & -1.08 & 0.82 & B24 & 8.6 & -1.47 & 0.19 \\
\hline B5 & 19.0 & -1.53 & 0.27 & B25 & 7.8 & -1.51 & 0.02 \\
\hline B6 & -4.3 & -1.70 & 0.36 & B26 & 4.4 & -1.23 & 0.11 \\
\hline B7 & -9.7 & -1.27 & 0.49 & B27 & 16.1 & -1.80 & 0.41 \\
\hline
\end{tabular}




\begin{tabular}{|c|c|c|c|c|c|c|c|}
\hline B8 & 9.1 & -1.32 & 0.53 & B28 & 16.1 & -1.83 & 0.24 \\
\hline B9 & 9.1 & -1.46 & 0.31 & B29 & 12.5 & -2.28 & 0.13 \\
\hline B10 & 14.1 & -1.67 & 0.30 & B30 & 2.9 & -0.95 & 0.33 \\
\hline B11 & 3.8 & -0.80 & 0.73 & B31 & 10.7 & -2.26 & 0.12 \\
\hline B12 & 5.2 & -1.89 & 0.26 & B32 & 8.7 & -1.86 & 0.55 \\
\hline B13 & -7.2 & -1.47 & 0.39 & B33 & 13.7 & -1.43 & 0.02 \\
\hline B14 & 15.0 & -1.47 & 0.11 & B34 & 6.2 & -1.65 & 0.44 \\
\hline B15 & 10.7 & -1.95 & 0.23 & B35 & 7.8 & -1.94 & 0.20 \\
\hline B16 & 5.9 & 1.09 & 0.80 & B36 & 1.5 & -1.73 & 0.19 \\
\hline B17 & 5.1 & -1.87 & 0.31 & B37 & 16.1 & -0.67 & 0.23 \\
\hline B18 & 15.2 & -0.95 & 0.17 & B38 & -10.2 & -1.49 & 0.75 \\
\hline B19 & 3.9 & -1.81 & 0.22 & B39 & 3.5 & -1.75 & 0.38 \\
\hline B20 & -9.3 & -1.29 & 0.94 & B40 & 4.1 & -1.84 & 0.30 \\
\hline
\end{tabular}

Table S12. Calculated ${ }^{11} \mathrm{~B}$ NMR parameters in the $\mathrm{Na}_{27}\left(\mathrm{~B}_{5} \mathrm{C}\right)_{27}$ model 1 Crandom 333 .

\begin{tabular}{|c|c|c|c|c|c|c|c|c|c|c|c|}
\hline & $\begin{array}{c}\delta_{\text {iso }} \\
(\mathrm{ppm})\end{array}$ & $\begin{array}{c}\mathrm{C}_{Q} \\
(\mathrm{MHz})\end{array}$ & $\eta$ & $\begin{array}{c}\delta_{\text {iso }} \\
(\mathrm{ppm})\end{array}$ & $\begin{array}{c}\mathrm{C}_{Q} \\
(\mathrm{MHz})\end{array}$ & $\eta$ & & $\begin{array}{c}\delta_{\text {iso }} \\
(\mathrm{ppm})\end{array}$ & $\begin{array}{c}\mathrm{C}_{Q} \\
(\mathrm{MHz})\end{array}$ & $\eta$ \\
\hline $\mathrm{B} 1$ & 2.3 & -1.84 & 0.18 & $\mathrm{~B} 46$ & 16.6 & -1.58 & 0.12 & $\mathrm{~B} 91$ & 6.7 & -1.73 & 0.23 \\
\hline B2 & -5.6 & -1.54 & 0.38 & $\mathrm{~B} 47$ & -7.9 & -1.56 & 0.45 & $\mathrm{~B} 92$ & 16.2 & -1.56 & 0.11 \\
\hline B3 & 4.6 & -1.55 & 0.10 & $\mathrm{~B} 48$ & 2.0 & -1.36 & 0.03 & $\mathrm{~B} 93$ & 2.7 & -1.80 & 0.54 \\
\hline B4 & 5.2 & -1.18 & 0.20 & $\mathrm{~B} 49$ & -10.9 & -1.62 & 0.18 & $\mathrm{~B} 94$ & 4.1 & -1.41 & 0.39 \\
\hline B5 & 6.1 & -1.30 & 0.10 & $\mathrm{~B} 50$ & 4.8 & -1.75 & 0.48 & $\mathrm{~B} 95$ & 13.4 & -1.42 & 0.45 \\
\hline B6 & 5.5 & -1.54 & 0.41 & $\mathrm{~B} 51$ & 4.3 & -1.25 & 0.69 & $\mathrm{~B} 96$ & 5.5 & -1.09 & 0.77 \\
\hline B7 & 5.2 & -1.50 & 0.32 & $\mathrm{~B} 52$ & -8.6 & -1.58 & 0.18 & $\mathrm{~B} 97$ & 4.8 & -1.66 & 0.27 \\
\hline B8 & 6.0 & -1.71 & 0.52 & $\mathrm{~B} 53$ & 6.5 & -1.71 & 0.28 & $\mathrm{~B} 98$ & -5.1 & -1.62 & 0.39 \\
\hline B9 & 5.9 & -1.80 & 0.42 & $\mathrm{~B} 54$ & 6.6 & -1.82 & 0.41 & $\mathrm{~B} 99$ & -4.8 & -1.46 & 0.20 \\
\hline B10 & 18.9 & -1.54 & 0.30 & $\mathrm{~B} 55$ & 6.5 & -1.13 & 0.58 & $\mathrm{~B} 100$ & 15.9 & -1.54 & 0.10 \\
\hline B11 & 6.2 & -1.70 & 0.23 & $\mathrm{~B} 56$ & 6.4 & -1.66 & 0.52 & $\mathrm{~B} 101$ & 3.6 & -1.80 & 0.32 \\
\hline B12 & 6.2 & -1.79 & 0.37 & $\mathrm{~B} 57$ & 5.0 & -1.65 & 0.35 & $\mathrm{~B} 102$ & 8.8 & -1.66 & 0.17 \\
\hline B13 & 2.0 & -1.62 & 0.35 & $\mathrm{~B} 58$ & 15.7 & -1.56 & 0.06 & $\mathrm{~B} 103$ & 14.6 & -0.69 & 0.24 \\
\hline
\end{tabular}




\begin{tabular}{|c|c|c|c|c|c|c|c|c|c|c|c|}
\hline B14 & 13.3 & -1.77 & 0.12 & B59 & 17.2 & -1.01 & 0.25 & B104 & 5.8 & -1.61 & 0.51 \\
\hline B15 & -5.2 & -1.43 & 0.15 & B60 & -9.2 & -1.53 & 0.39 & B105 & 5.0 & -1.61 & 0.39 \\
\hline B16 & 4.3 & -1.02 & 0.70 & B61 & 5.9 & -1.71 & 0.28 & B106 & 3.0 & -1.66 & 0.30 \\
\hline B17 & -5.4 & -1.02 & 0.56 & B62 & 6.7 & -1.47 & 0.62 & B107 & 3.5 & -1.10 & 0.33 \\
\hline B18 & 3.4 & -0.94 & 0.75 & B63 & -7.4 & -1.51 & 0.55 & B108 & 4.6 & -1.64 & 0.26 \\
\hline B19 & -5.6 & -0.94 & 0.68 & B64 & 3.9 & -1.62 & 0.40 & B109 & 5.5 & -1.74 & 0.25 \\
\hline B20 & 16.5 & -1.56 & 0.35 & B65 & 4.6 & -1.75 & 0.30 & B110 & 17.8 & -1.62 & 0.07 \\
\hline B21 & 5.4 & -1.57 & 0.28 & B66 & 2.3 & -1.83 & 0.43 & B111 & 5.0 & -1.61 & 0.56 \\
\hline B22 & 5.3 & -1.62 & 0.35 & B67 & 19.2 & -1.40 & 0.11 & B112 & 7.0 & -1.56 & 0.71 \\
\hline B23 & 16.2 & -1.64 & 0.32 & B68 & 17.7 & -1.48 & 0.22 & B113 & 15.2 & -1.66 & 0.04 \\
\hline B24 & 4.3 & -1.64 & 0.15 & B69 & 5.5 & -1.64 & 0.14 & B114 & 4.5 & -1.90 & 0.47 \\
\hline B25 & 3.7 & -1.65 & 0.48 & B70 & 5.8 & -1.23 & 0.65 & B115 & 8.3 & -1.35 & 0.15 \\
\hline B26 & 18.2 & -1.60 & 0.24 & B71 & 15.8 & -1.58 & 0.04 & B116 & -7.9 & -1.55 & 0.54 \\
\hline B27 & 2.6 & 1.24 & 0.89 & B72 & 5.9 & -1.53 & 0.44 & B117 & 4.0 & -1.82 & 0.53 \\
\hline B28 & 16.2 & -1.72 & 0.26 & B73 & -10.2 & -1.43 & 0.33 & B118 & 7.6 & -1.33 & 0.92 \\
\hline B29 & 4.9 & -1.66 & 0.23 & B74 & 5.8 & -1.73 & 0.17 & B119 & 6.1 & -1.12 & 0.70 \\
\hline B30 & -2.2 & -0.97 & 0.72 & B75 & 19.6 & -1.54 & 0.10 & B120 & 4.5 & -1.14 & 0.65 \\
\hline B31 & 5.9 & -1.18 & 0.66 & B76 & 6.1 & -1.57 & 0.41 & B121 & -9.3 & -1.42 & 0.59 \\
\hline B32 & 4.4 & -1.74 & 0.58 & B77 & 3.7 & -1.81 & 0.47 & B122 & 12.5 & -1.65 & 0.22 \\
\hline B33 & -2.2 & -0.94 & 0.91 & B78 & 17.4 & -1.55 & 0.26 & B123 & -5.7 & -1.60 & 0.35 \\
\hline B34 & -6.0 & -1.49 & 0.96 & B79 & 6.2 & -1.73 & 0.28 & B124 & 2.5 & -1.62 & 0.26 \\
\hline B35 & 3.3 & -1.68 & 0.34 & B80 & 4.7 & -1.79 & 0.32 & B125 & -8.4 & -1.52 & 0.59 \\
\hline B36 & 7.6 & -1.18 & 0.28 & B81 & 5.7 & -1.70 & 0.40 & B126 & -9.6 & -1.37 & 0.19 \\
\hline B37 & 6.0 & -1.79 & 0.40 & B82 & 5.9 & -1.61 & 0.31 & B127 & 5.7 & -1.68 & 0.32 \\
\hline B38 & 15.5 & -1.54 & 0.02 & B83 & 4.1 & -1.75 & 0.34 & B128 & 6.9 & -1.74 & 0.38 \\
\hline B39 & 5.4 & -1.72 & 0.34 & B84 & 2.7 & -1.77 & 0.67 & B129 & 3.5 & -1.89 & 0.44 \\
\hline B40 & 3.3 & -1.48 & 0.14 & B85 & 5.1 & -1.68 & 0.53 & B130 & 6.5 & -1.82 & 0.55 \\
\hline B41 & 15.3 & -1.69 & 0.11 & B86 & 3.5 & -1.73 & 0.44 & B131 & 16.3 & -1.66 & 0.14 \\
\hline B42 & -8.1 & -1.46 & 0.50 & B87 & 6.7 & -1.17 & 0.45 & B132 & 3.7 & -1.72 & 0.40 \\
\hline B43 & 2.8 & -1.18 & 0.38 & B88 & 6.2 & -1.71 & 0.37 & B133 & 3.9 & -1.13 & 0.70 \\
\hline B44 & 5.4 & -1.54 & 0.64 & B89 & 3.9 & -1.66 & 0.26 & B134 & 4.8 & -1.68 & 0.38 \\
\hline
\end{tabular}




\begin{tabular}{|c|c|c|c|c|c|c|c|c|c|c|c|}
\hline B45 & 1.8 & -1.54 & 0.45 & B90 & 5.0 & -1.61 & 0.32 & B135 & 6.9 & -1.72 & 0.31 \\
\hline
\end{tabular}

Table S13. Calculated ${ }^{11} \mathrm{~B}$ NMR parameters in the $\mathrm{Na}_{7}\left(\mathrm{~B}_{5} \mathrm{C}\right) 7\left(\mathrm{~B}_{4} \mathrm{C}_{2}\right)$ model 1-Na-1C2 Crandom 222.

\begin{tabular}{|c|c|c|c|c|c|c|c|}
\hline & $\delta_{\text {iso }}(\mathrm{ppm})$ & $C_{Q}(\mathrm{MHz})$ & $\eta$ & & $\delta_{\text {iso }}(\mathrm{ppm})$ & $C_{Q}(\mathrm{MHz})$ & $\eta$ \\
\hline B1 & -0.4 & -0.67 & 0.84 & B21 & 4.9 & -1.74 & 0.21 \\
\hline B2 & -3.7 & -1.52 & 0.26 & B22 & 0.9 & -1.54 & 0.36 \\
\hline B3 & 1.9 & -1.71 & 0.53 & B23 & 17.7 & -1.53 & 0.32 \\
\hline B4 & 4.6 & -0.96 & 0.77 & B24 & 3.6 & -1.73 & 0.35 \\
\hline B5 & 17.1 & -1.48 & 0.45 & B25 & 4.9 & -1.65 & 0.47 \\
\hline B6 & -5.5 & -1.66 & 0.35 & B26 & 17.0 & -1.94 & 0.55 \\
\hline B7 & -8.6 & -1.31 & 0.54 & B27 & 19.4 & -1.94 & 0.28 \\
\hline B8 & 9.8 & -1.42 & 0.60 & B28 & 10.3 & -2.24 & 0.17 \\
\hline B9 & 14.8 & -1.67 & 0.34 & B29 & 2.1 & -0.93 & 0.38 \\
\hline B10 & 1.4 & -0.73 & 0.66 & B30 & 6.9 & -2.09 & 0.10 \\
\hline B11 & 4.4 & -1.77 & 0.21 & B31 & -7.2 & -1.45 & 0.73 \\
\hline B12 & -10.6 & -1.45 & 0.26 & B32 & 14.7 & -1.60 & 0.05 \\
\hline B13 & 16.8 & -1.49 & 0.18 & B33 & 4.0 & -1.69 & 0.27 \\
\hline B14 & 4.8 & -1.71 & 0.30 & B34 & 7.3 & -1.20 & 0.60 \\
\hline B15 & 6.3 & 1.08 & 0.95 & B35 & -0.2 & -1.68 & 0.23 \\
\hline B16 & 3.7 & -1.82 & 0.33 & B36 & 16.8 & -0.71 & 0.25 \\
\hline B17 & 14.4 & -0.91 & 0.18 & B37 & -9.4 & -1.53 & 0.75 \\
\hline B18 & 5.3 & -1.84 & 0.17 & B38 & 5.0 & -1.81 & 0.37 \\
\hline B19 & -7.2 & -1.33 & 0.92 & B39 & 5.0 & -1.86 & 0.26 \\
\hline B20 & 6.4 & -1.74 & 0.38 & & & & \\
\hline & & & & & & & \\
\hline
\end{tabular}

Table S14. Calculated ${ }^{11} \mathrm{~B}$ NMR parameters in the $\mathrm{Na}_{24}\left(\mathrm{~B}_{5} \mathrm{C}\right)_{24}\left(\mathrm{~B}_{4} \mathrm{C}_{2}\right)_{3}$ model 3-Na-1C2 Crandom 333.

\begin{tabular}{|c|c|c|c|c|c|c|c|c|c|c|c|}
\hline & $\begin{array}{c}\delta_{\text {iso }} \\
(\mathrm{ppm})\end{array}$ & $\begin{array}{c}\mathrm{C}_{Q} \\
(\mathrm{MHz})\end{array}$ & $\eta$ & & $\begin{array}{c}\delta_{\text {iso }} \\
(\mathrm{ppm})\end{array}$ & $\begin{array}{c}\mathrm{C}_{Q} \\
(\mathrm{MHz})\end{array}$ & $\eta$ & & $\begin{array}{c}\delta_{\text {iso }} \\
(\mathrm{ppm})\end{array}$ & $\begin{array}{c}\mathrm{C}_{Q} \\
(\mathrm{MHz})\end{array}$ & $\eta$ \\
\hline
\end{tabular}




\begin{tabular}{|c|c|c|c|c|c|c|c|c|c|c|c|}
\hline B1 & -1.7 & -1.61 & 0.15 & B45 & 16.8 & -1.51 & 0.18 & B89 & -1.0 & -1.45 & 0.36 \\
\hline B2 & -6.9 & -1.52 & 0.43 & B46 & -6.5 & -1.59 & 0.29 & B90 & 15.4 & -1.56 & 0.07 \\
\hline B3 & 5.1 & -1.49 & 0.08 & B47 & 1.5 & -1.29 & 0.09 & B91 & 3.3 & -1.89 & 0.36 \\
\hline B4 & 4.1 & -1.12 & 0.17 & B48 & -9.1 & -1.66 & 0.18 & B92 & 17.9 & -1.71 & 0.11 \\
\hline B5 & 3.9 & -1.35 & 0.05 & B49 & 17.6 & -2.06 & 0.35 & B93 & 17.5 & -1.87 & 0.50 \\
\hline B6 & 7.2 & -1.64 & 0.45 & B50 & 3.8 & -1.24 & 0.93 & B94 & 3.1 & -1.47 & 0.13 \\
\hline B7 & 5.2 & -1.47 & 0.35 & B51 & -7.3 & -1.58 & 0.20 & B95 & -3.5 & -2.05 & 0.14 \\
\hline B8 & 1.2 & -1.61 & 0.65 & B52 & 7.0 & -1.70 & 0.25 & B96 & -1.1 & -1.54 & 0.11 \\
\hline B9 & 7.1 & -1.78 & 0.30 & B53 & 7.6 & -1.83 & 0.40 & B97 & 13.1 & -0.45 & 0.49 \\
\hline B10 & 19.3 & -1.61 & 0.19 & B54 & 3.6 & -0.97 & 0.80 & B98 & 5.6 & -2.00 & 0.34 \\
\hline B11 & 8.6 & -1.72 & 0.42 & B55 & 5.1 & -1.64 & 0.57 & B99 & 5.8 & -1.66 & 0.17 \\
\hline B12 & 5.5 & -1.76 & 0.43 & B56 & 4.5 & -1.65 & 0.37 & B100 & 12.0 & -0.51 & 0.64 \\
\hline B13 & 4.4 & -1.70 & 0.44 & B57 & 15.3 & -1.56 & 0.06 & B101 & 4.2 & -1.55 & 0.48 \\
\hline B14 & 15.7 & -1.85 & 0.18 & B58 & 12.7 & -0.65 & 0.53 & B102 & 5.4 & -1.67 & 0.37 \\
\hline B15 & -7.2 & -1.21 & 0.25 & B59 & -5.0 & -1.63 & 0.27 & B103 & 2.8 & -1.70 & 0.22 \\
\hline B16 & 3.7 & -0.98 & 0.81 & B60 & 5.6 & -1.67 & 0.22 & B104 & 4.4 & -1.11 & 0.47 \\
\hline B17 & -4.8 & -1.20 & 0.63 & B61 & 6.0 & -1.55 & 0.68 & B105 & 1.7 & -1.44 & 0.24 \\
\hline B18 & 3.3 & -0.83 & 0.75 & B62 & -5.9 & -1.94 & 0.18 & B106 & 7.4 & -1.79 & 0.18 \\
\hline B19 & -6.0 & -1.03 & 0.53 & B63 & 3.9 & -2.06 & 0.18 & B107 & 17.1 & -1.56 & 0.02 \\
\hline B20 & 19.7 & -1.56 & 0.24 & B64 & 1.1 & -1.86 & 0.41 & B108 & 4.4 & -1.52 & 0.57 \\
\hline B21 & 9.2 & -1.62 & 0.24 & B65 & 24.4 & -1.99 & 0.04 & B109 & 2.4 & -1.39 & 0.73 \\
\hline B22 & 11.4 & -1.88 & 0.28 & B66 & 17.5 & -1.45 & 0.23 & B110 & 17.5 & -1.75 & 0.03 \\
\hline B23 & 13.9 & -1.35 & 0.45 & B67 & 4.7 & -1.60 & 0.11 & B111 & 5.3 & -1.96 & 0.60 \\
\hline B24 & 0.6 & -1.48 & 0.39 & B68 & 8.1 & -1.10 & 0.73 & B112 & 8.8 & -1.22 & 0.26 \\
\hline B25 & 2.8 & -1.67 & 0.39 & B69 & 17.5 & -1.69 & 0.05 & B113 & -6.8 & -1.53 & 0.56 \\
\hline B26 & 22.0 & -1.75 & 0.20 & B70 & 6.2 & -1.62 & 0.31 & B114 & 4.2 & -1.92 & 0.43 \\
\hline B27 & 1.2 & 1.20 & 0.82 & B71 & -12.8 & -1.17 & 0.51 & B115 & 7.7 & 1.35 & 0.95 \\
\hline B28 & 18.8 & -1.78 & 0.19 & B72 & 7.0 & -1.80 & 0.05 & B116 & 2.4 & 0.90 & 0.79 \\
\hline B29 & 6.3 & -1.65 & 0.38 & B73 & 20.6 & -2.05 & 0.02 & B117 & 4.3 & -1.29 & 0.79 \\
\hline B30 & -0.8 & -1.12 & 0.75 & B74 & 8.6 & -1.63 & 0.34 & B118 & -8.2 & -1.50 & 0.61 \\
\hline B31 & 8.4 & -1.34 & 0.79 & B75 & 6.0 & -1.82 & 0.36 & B119 & 16.1 & -1.68 & 0.19 \\
\hline
\end{tabular}




\begin{tabular}{|c|c|c|c|c|c|c|c|c|c|c|c|}
\hline B32 & 2.4 & -1.67 & 0.53 & B76 & 16.0 & -1.47 & 0.23 & B120 & -5.9 & -1.69 & 0.36 \\
\hline B33 & -3.2 & 0.94 & 0.96 & B77 & 3.4 & -1.67 & 0.37 & B121 & -2.3 & -1.55 & 0.38 \\
\hline B34 & -3.2 & 1.41 & 0.13 & B78 & 2.3 & -1.69 & 0.41 & B122 & -9.6 & -1.44 & 0.55 \\
\hline B35 & 1.2 & -1.66 & 0.21 & B79 & 16.8 & -1.96 & 0.25 & B123 & -9.6 & -1.37 & 0.11 \\
\hline B36 & 0.2 & -1.00 & 0.30 & B80 & 6.1 & -1.61 & 0.37 & B124 & 5.3 & -1.62 & 0.29 \\
\hline B37 & 7.3 & -1.92 & 0.37 & B81 & 3.6 & -1.76 & 0.30 & B125 & -3.2 & -1.46 & 0.49 \\
\hline B38 & 17.2 & -1.70 & 0.05 & B82 & 5.0 & -1.66 & 0.78 & B126 & 5.7 & -2.02 & 0.29 \\
\hline B39 & 2.3 & -1.47 & 0.22 & B83 & 6.0 & -1.72 & 0.54 & B127 & 3.8 & 1.05 & 0.75 \\
\hline B40 & 17.7 & -1.74 & 0.11 & B84 & 6.3 & -2.17 & 0.19 & B128 & 15.9 & -1.65 & 0.19 \\
\hline B41 & -6.2 & -1.55 & 0.59 & B85 & 5.3 & -1.56 & 0.21 & B129 & 0.4 & -1.73 & 0.40 \\
\hline B42 & 4.3 & -1.28 & 0.57 & B86 & 3.4 & -1.70 & 0.30 & B130 & 4.0 & -1.16 & 0.57 \\
\hline B43 & 5.5 & -1.55 & 0.75 & B87 & 10.2 & -1.78 & 0.22 & B131 & 1.0 & -1.47 & 0.53 \\
\hline B44 & 1.8 & -1.57 & 0.55 & B88 & 7.4 & -1.72 & 0.24 & B132 & 5.1 & -1.70 & 0.23 \\
\hline
\end{tabular}

Table S15. Calculated ${ }^{23} \mathrm{Na}$ NMR parameters in the $\mathrm{Na}_{8}\left(\mathrm{~B}_{5} \mathrm{C}\right)_{8}$ model 1Crandom222, $\mathrm{Na}_{8}\left(\mathrm{~B}_{5} \mathrm{C}\right)_{6}\left(\mathrm{~B}_{4} \mathrm{C}_{2}\right)\left(\mathrm{B}_{6}\right)$ model $\mathbf{0 C}-2 \mathrm{Crandom} 222$ and $\mathrm{Na}_{7}\left(\mathrm{~B}_{5} \mathrm{C}\right)_{7}\left(\mathrm{~B}_{4} \mathrm{C}_{2}\right)$ model 1-Na-1C2Crandom222.

\begin{tabular}{|l|c|c|c|c|c|c|c|c|c|}
\hline & \multicolumn{3}{|c|}{ 1Crandom222 } & \multicolumn{3}{c|}{ 0C-2Crandom222 } & \multicolumn{2}{c|}{ 1-Na-1C-2Crandom222 } \\
\hline & $\begin{array}{c}\delta_{\text {iso }} \\
(\mathrm{ppm})\end{array}$ & $\begin{array}{c}\mathrm{C}_{Q} \\
(\mathrm{MHz})\end{array}$ & $\eta$ & $\begin{array}{c}\delta_{\text {iso }} \\
(\mathrm{ppm})\end{array}$ & $\begin{array}{c}\mathrm{C}_{Q} \\
(\mathrm{MHz})\end{array}$ & $\eta$ & $\begin{array}{c}\delta_{\text {iso }} \\
(\mathrm{ppm})\end{array}$ & $\begin{array}{c}\mathrm{C}_{Q} \\
(\mathrm{MHz})\end{array}$ & $\eta$ \\
\hline $\mathrm{Na} 1$ & -11.9 & 0.70 & 0.77 & -10.2 & 1.07 & 0.11 & -12.1 & -0.92 & 0.31 \\
\hline $\mathrm{Na} 2$ & -11.7 & 0.81 & 0.33 & -4.6 & 1.23 & 0.39 & -6.7 & 1.01 & 0.11 \\
\hline $\mathrm{Na} 3$ & -9.2 & 0.58 & 0.16 & -8.4 & 0.93 & 0.77 & -11.1 & -0.69 & 0.38 \\
\hline $\mathrm{Na} 4$ & -12.7 & 0.47 & 0.92 & -8.4 & 1.01 & 0.73 & -11.3 & 0.69 & 0.93 \\
\hline $\mathrm{Na} 5$ & -11.6 & 0.89 & 0.46 & -7.4 & -1.09 & 0.79 & -10.7 & -0.82 & 0.85 \\
\hline $\mathrm{Na} 6$ & -13.2 & 0.47 & 0.55 & -12.7 & 0.76 & 0.61 & -13.5 & 0.51 & 0.92 \\
\hline $\mathrm{Na} 7$ & -12.3 & 0.91 & 0.49 & -11.7 & 1.05 & 0.61 & -6.1 & 0.88 & 0.46 \\
\hline $\mathrm{Na} 8$ & -9.1 & 0.73 & 0.41 & -3.0 & -1.09 & 0.93 & & & \\
\hline
\end{tabular}


Table S16. Calculated ${ }^{23} \mathrm{Na}$ NMR parameters in the $\mathrm{Na}_{27}\left(\mathrm{~B}_{5} \mathrm{C}\right)_{27}$ model $\mathbf{1 C r a n d o m} 333$ and $\mathrm{Na}_{24}\left(\mathrm{~B}_{5} \mathrm{C}\right)_{24}\left(\mathrm{~B}_{4} \mathrm{C}_{2}\right)_{3}$ model 3Na-1C-2Crandom 333 .

\begin{tabular}{|c|c|c|c|c|c|c|}
\hline & \multicolumn{3}{|c|}{ 1Crandom 333} & \multicolumn{3}{|c|}{ 3Na-1C-2Crandom333 } \\
\hline & $\delta_{\text {iso }}(\mathrm{ppm})$ & $C_{Q}(\mathrm{MHz})$ & $\eta$ & $\delta_{\text {iso }}(\mathrm{ppm})$ & $C_{Q}(\mathrm{MHz})$ & $\eta$ \\
\hline $\mathrm{Na1}$ & -11.4 & 0.48 & 0.30 & -9.4 & 0.43 & 0.80 \\
\hline $\mathrm{Na} 2$ & -11.3 & -0.47 & 0.48 & -11.3 & -0.46 & 0.29 \\
\hline Na3 & -15.4 & 0.57 & 0.76 & -13.9 & 0.53 & 0.86 \\
\hline $\mathrm{Na} 4$ & -11.8 & -0.36 & 0.02 & -14.2 & 0.81 & 0.51 \\
\hline $\mathrm{Na5}$ & -13.7 & 0.53 & 0.60 & -12.6 & 0.58 & 0.93 \\
\hline $\mathrm{Na6}$ & -11.3 & -0.55 & 0.58 & -9.4 & 1.17 & 0.06 \\
\hline $\mathrm{Na7}$ & -11.3 & 0.85 & 0.08 & -7.3 & -0.88 & 0.76 \\
\hline $\mathrm{Na} 8$ & -8.9 & -0.66 & 0.45 & -15.0 & -0.82 & 0.89 \\
\hline Na9 & -14.9 & 0.55 & 0.79 & -12.8 & -0.52 & 0.87 \\
\hline Na10 & -14.5 & -0.47 & 0.87 & -7.6 & -0.33 & 0.55 \\
\hline Na11 & -13.6 & -0.48 & 0.32 & -10.4 & 1.18 & 0.47 \\
\hline $\mathrm{Na} 12$ & -8.6 & -0.43 & 0.61 & -9.9 & -0.49 & 0.65 \\
\hline $\mathrm{Na13}$ & -11.4 & -0.50 & 0.72 & -7.5 & 0.69 & 0.79 \\
\hline Na14 & -12.3 & 0.41 & 0.27 & -6.3 & 0.79 & 0.14 \\
\hline Na15 & -14.5 & 0.25 & 0.51 & -8.2 & 0.75 & 0.65 \\
\hline Na16 & -7.6 & 0.75 & 0.87 & -6.5 & -0.54 & 0.09 \\
\hline Na17 & -6.3 & 0.57 & 0.67 & -10.9 & 1.07 & 0.21 \\
\hline Na18 & -8.0 & 0.74 & 0.12 & -10.6 & 0.51 & 0.86 \\
\hline Na19 & -11.1 & 0.55 & 0.59 & -8.0 & 1.47 & 0.45 \\
\hline $\mathrm{Na} 20$ & -12.8 & 0.57 & 0.28 & -13.9 & -0.41 & 0.90 \\
\hline $\mathrm{Na} 21$ & -10.3 & 0.62 & 0.40 & -9.5 & -0.55 & 0.56 \\
\hline $\mathrm{Na} 22$ & -9.5 & 0.56 & 0.81 & -9.5 & 0.59 & 0.74 \\
\hline $\mathrm{Na} 23$ & -13.4 & -0.33 & 0.53 & -9.5 & 0.99 & 0.35 \\
\hline $\mathrm{Na} 24$ & -9.3 & -0.57 & 0.60 & -13.7 & 0.44 & 0.40 \\
\hline $\mathrm{Na} 25$ & -13.0 & 0.23 & 0.14 & & & \\
\hline $\mathrm{Na} 26$ & -7.9 & 1.27 & 0.16 & & & \\
\hline $\mathrm{Na} 27$ & -13.6 & 0.38 & 0.78 & & & \\
\hline
\end{tabular}

